\title{
VARIABILIDADE ESPACIAL DO TEOR DE ÁGUA E SUA INFLUÊNCIA NA CONDUTIVIDADE ELÉTRICA DO SOLO
}

\author{
GuSTAVo Di CHIACCHIO FAULIN
}

Dissertação apresentada à Escola Superior de Agricultura "Luiz de Queiroz", Universidade de São Paulo, para obtenção do título de Mestre em Agronomia, Área de Concentração: Máquinas Agrícolas.

P I R A C I C A B A

Estado de São Paulo - Brasil

Julho - 2005 


\title{
VARIABILIDADE ESPACIAL DO TEOR DE ÁGUA E SUA INFLUÊNCIA NA CONDUTIVIDADE ELÉTRICA DO SOLO
}

\section{GuSTAVo Di ChIACCHIO FAULIN}

Engenheiro Agrônomo

\author{
Orientador: Prof. Dr. JOSÉ PAULO MOLIN
}

\begin{abstract}
Dissertação apresentada à Escola Superior de Agricultura "Luiz de Queiroz", Universidade de São Paulo, para obtenção do título de Mestre em Agronomia, Área de Concentração: Máquinas Agrícolas.
\end{abstract}

P I R A C I C A B A

Estado de São Paulo - Brasil Julho - 2005 
Dados Internacionais de Catalogação na Publicação (CIP) DIVISÃO DE BIBLIOTECA E DOCUMENTAÇÃO - ESALQ/USP

Faulin, Gustavo Di Chiacchio

Variabilidade espacial do teor de água e sua influência na condutividade elétrica do solo / Gustavo Di Chiacchio Faulin. - - Piracicaba, 2005.

52 p. : il.

Dissertação (Mestrado) - - Escola Superior de Agricultura Luiz de Queiroz, 2005.

Bibliografia.

1. Agricultura de precisão 2. Condutividade elétrica do solo 3. Fertilidade do solo Física do solo 5. Geoestatística 6. Teor de água 7. Variabilidade I. Título

CDD 631.432

"Permitida a cópia total ou parcial deste documento, desde que citada a fonte - $\mathrm{O}$ autor" 
“O que antes parecia impossível torna-se possível quando alguém se sente apto a transpor todos os obstáculos, conhecendo sua verdadeira grandeza interior” Nuno Cobra

Aos que lutam por um mundo cada dia melhor OFEREÇO

Aos meus pais João e Maria Ângela Grandes exemplos e grandes amigos

Aos meus avós Antônio (In memorian) e Mariana José e Maria Pelo carinho, apoio e referência

À minha noiva Marisa Sempre presente em minha vida A essas pessoas que tanto amo DEDICO 


\section{AGRADECIMENTOS}

À Escola Superior de Agricultura "Luiz de Queiroz" - Universidade de São Paulo, Departamento de Engenharia Rural, pela oportunidade de realizar este curso de Mestrado.

Ao Conselho Nacional de Desenvolvimento Científico e Tecnológico (CNPq) pela concessão da bolsa de estudos.

À Fundação de Amparo à Pesquisa do Estado de São Paulo (FAPESP) pelo financiamento do projeto.

Ao Professor Dr. José Paulo Molin pela orientação, pelo exemplo de competência, ética e dedicação ao ensino, sobretudo pela confiança e amizade.

À Fundação ABC, em especial ao amigo Pesquisador Eng ${ }^{\circ}$ Agrônomo Leandro M. Gimenez, e proprietários da fazenda Irmãos Borges e fazenda Sol, sempre dispostos a colaborar e que muito contribuíram para a realização desse trabalho.

Aos colegas de pós-graduação em máquinas agrícolas, em especial César (Slot), Adriano (Tereré), Gustavo Fontana, Gustavo Kazuo, Raphael (Bríu), Leonardo, Thiago, José Vitor, Flávia (Rô-dízio), Pedro (Mr. ISO), Rubén e Cassiano pelo apoio e troca de experiências.

Aos estagiários do Grupo de Mecanização e Agricultura de Precisão (gMAP), Gabriel (Boléro), Rodrigo (Osvaldo), Lucelha (Incendiária), Pablo (K-fetão) e Wilson (Koxêti).

Aos professores do Departamento de Engenharia Rural pela colaboração e pelo apoio.

Aos colegas do Departamento de Engenharia Rural, Juarez, Áureo, Afonso, Francisco, Fernanda, Dona Lourdes, José Ferreira (Juquita), José Geraldo, Dona Vera e Hilda pela amizade, suporte técnico e operacional. 


\section{SUMÁRIO}

Página

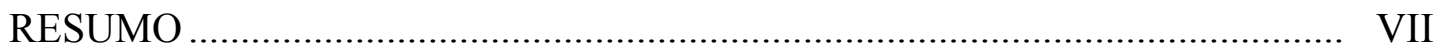

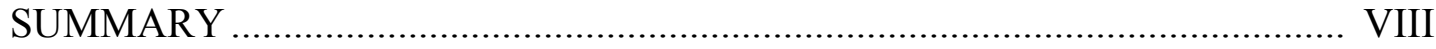

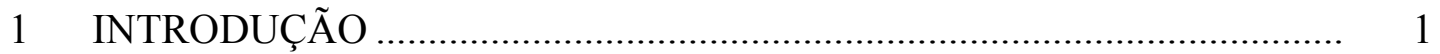

2 REVISÃO DE LITERATURA ……....................................................... 3

2.1 Teor de água no solo........................................................................... 3

2.2 Condutividade elétrica do solo ............................................................. 5

2.3 Características físico-químicas do solo e condutividade elétrica .................. 9

2.4 Estatística descritiva, dependência espacial e geoestatística ....................... 11

3 MATERIAL E MÉTODOS ................................................................. 14

$4 \quad$ RESULTADOS E DISCUSSÃO ........................................................... 20

5 CONCLUSÕES ....................................................................... 38

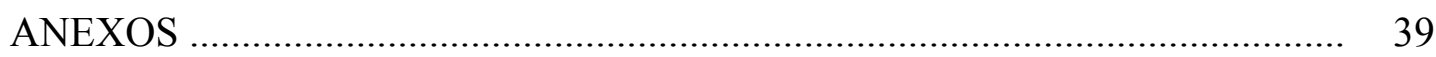




\title{
VARIABILIDADE ESPACIAL DO TEOR DE ÁGUA E SUA INFLUÊNCIA NA CONDUTIVIDADE ELÉTRICA DO SOLO
}

\author{
Autor: GUSTAVO DI CHIACCHIO FAULIN
}

Orientador: Prof. Dr. JOSÉ PAULO MOLIN

\section{RESUMO}

A agricultura de precisão pode ser definida como o gerenciamento da produção levando em consideração a variabilidade espacial da produtividade e dos fatores a ela relacionados, visando otimizar os insumos e permitindo a diminuição nos custos de produção. Uma forma de mapeamento de fatores do solo é o monitoramento da condutividade elétrica que permite inferir sobre variáveis como textura, salinidade, teor de água, entre outros. Os mapas de condutividade elétrica do solo não excluem a análise de amostras em laboratório, porém fornecem uma orientação na execução de amostragens estratégicas através da identificação de zonas homogêneas. Esse trabalho dá continuidade a estudos de monitoramento da condutividade elétrica do solo, utilizando um sensor de condutividade elétrica por contato, em áreas experimentais aonde vêm sendo obtidas informações da variabilidade espacial dos fatores do solo e da produção. Não se tem, até o momento, o domínio da qualidade da informação relacionada à condutividade elétrica para solos brasileiros, sendo necessários estudos aprofundados, especialmente para as regiões de maior importância agrícola do país. Por outro lado, no solo, o teor de água é fortemente relacionado a várias de suas características físicas, inclusive a condutividade elétrica. Antecipando-se a problemas de interpretação da condutividade elétrica que possam advir da falta de informação do teor de água no 
solo, o objetivo do trabalho foi monitorar espacialmente o teor de água e modelar sua influência na condutividade elétrica. Foram realizadas análises estatísticas clássicas, análises exploratórias dos dados e análises geoestatísticas, gerando parâmetros para a obtenção de mapas interpolados das variáveis condutividade elétrica, teor de água e argila, estimando, através da krigagem, valores dessas variáveis em locais não amostrados e também possibilitando análises de regressões polinomiais entre as variáveis. Por meio das regressões foi possível observar que no solo grande parte da variação do teor de água pode ser explicada pela variação do teor de argila. Em uma das áreas, onde as amplitudes dos teores de argila são maiores, a variabilidade espacial da condutividade elétrica mostrou ser dependente do teor de água e conseqüentemente do teor de argila. Em outra área o teor de água não apresentou influência na variabilidade espacial da condutividade elétrica. 


\title{
SPATIAL VARIABILITY OF SOIL MOISTURE AND ITS INFLUENCE IN THE SOIL ELECTRICAL CONDUCTIVITY
}

\author{
Author: GUSTAVO DI CHIACCHIO FAULIN \\ Adviser: Prof. Dr. JOSÉ PAULO MOLIN
}

\section{SUMMARY}

Precision agriculture can be defined as the production management taking into account the spatial variability of yield and factors related, aiming to optimize the inputs and allowing the decrease of production costs. A way to monitor soil properties is by using electrical conductivity sensors which allows inferring about variables such as texture, salinity, moisture, etc. Maps of soil electrical conductivity do not exclude samples analysis in laboratory, however, they give an orientation in the execution of strategic samplings by the identification of homogeneous areas. This work gives continuity to studies of monitoring of the soil electrical conductivity, using an electrical conductivity sensor for contact, in experimental areas where has been obtained information of space variability of soil factors and yield. Information related to soil electrical conductivity is not well known for Brazilian soils, so it is important to conduct studies, especially for the agricultural areas of the country. On the other hand, soil moisture is strongly related the several of its physical properties, besides electrical conductivity. Foreseeing problems of interpretation of electrical conductivity information that can occur because of lack of information of soil moisture, the objective of this work was to spatially monitor soil moisture and to model its influence on electrical conductivity. Classic statistical analyses, data exploratory analyses and geoestatistic analyses were accomplished, generating 
parameters for interpolation maps of the: electrical conductivity, variables moisture and clay, estimating, through kriging, values of those variables in no sampled places and also making possible polynomials regressions analyses among the variables. Through the regressions it was possible to observe that, in the soil, great part of the moisture variation can be explained by the clay variation. In one of the areas, where the range of clay rate are larger, the spatial variability of the electrical conductivity showed to be dependent on the moisture and consequently on the clay. In another area the moisture not present any influence in the spatial variability of the electrical conductivity. 


\section{INTRODUÇÃO}

A agricultura de precisão pode ser definida como o gerenciamento da produção levando em consideração a variabilidade espacial da produtividade e dos fatores a ela relacionados, sendo uma técnica relativamente recente no Brasil e possivelmente, a frente de trabalho que apresenta as perspectivas mais promissoras na geração de novas técnicas agrícolas, visando otimizar os insumos e permitindo a diminuição nos custos de produção. Com a evolução e ampliação dos conceitos associados à agricultura de precisão, observa-se a incorporação na agricultura da tecnologia da informação, em função da quantidade necessária de informação gerada para se obter bons diagnósticos que resultem em recomendações técnica e economicamente viáveis, especialmente no que se refere à aplicação localizada de insumos.

$\mathrm{Na}$ agricultura de precisão, a obtenção de mapas de produtividade e a amostragem de solo têm elevada importância na obtenção de informações sobre a produção. A técnica de se amostrar intensamente o solo na obtenção de informação da variabilidade espacial dos seus componentes físicos e químicos tem sido alvo de críticas pelo seu elevado custo, tornando-se, por vezes, economicamente inviável em sistemas produtivos.

Novas tecnologias de sensoriamento direto ou remoto de fatores do meio ambiente, primordiais na produção agrícola, estão constantemente sendo geradas, aperfeiçoadas e difundidas. Uma série de idéias de sensores para monitorar propriedades físico-químicas do solo têm sido propostas, algumas já em caráter experimental ou para utilização comercial. É o caso dos diferentes modelos de sensores de condutividade elétrica do solo.

Um conceito de mapeamento de fatores do solo é o monitoramento da condutividade elétrica que permite inferir sobre variáveis como textura, salinidade, teor de água, entre outros. Os mapas de condutividade elétrica do solo não excluem a 
análise de amostras em laboratório, porém fornecem uma orientação na execução de amostragens estratégicas através da identificação de zonas homogêneas.

Esse trabalho dá continuidade a estudos de monitoramento da condutividade elétrica do solo, utilizando um sensor de condutividade elétrica por contato, em áreas experimentais aonde vêm sendo obtidas informações da variabilidade espacial dos fatores do solo e da produção. Não se tem, até o momento, o domínio da qualidade da informação relacionada à condutividade elétrica para solos brasileiros, sendo necessários estudos aprofundados, especialmente para as regiões de maior importância agrícola do país. Por outro lado, no solo, o teor de água é fortemente relacionado a várias de suas características físicas, inclusive a condutividade elétrica. Antecipando-se a problemas de interpretação da condutividade elétrica que possam advir da falta de informação do teor de água no solo, o objetivo do trabalho foi monitorar espacialmente o teor de água e modelar sua influência na condutividade elétrica. 


\section{REVISÃO DE LITERATURA}

\subsection{Teor de água no solo}

Os mecanismos de retenção de água no solo dependem da sua composição granulométrica, principalmente em tensões elevadas. Vários trabalhos têm procurado relacionar retenção de água com composição granulométrica. Russo e Bresler (1981) salientam que as propriedades hidráulicas do solo geralmente não variam aleatoriamente no espaço, mas apresentam arranjo estrutural com uma dimensão característica, correspondente ao domínio desta propriedade, ou seja, a distância dentro da qual há interdependência dos valores medidos. Segundo Ahuja e Nielsen (1990), isto decorre das características do material originário e da ação dos fatores de formação.

Babalola (1978) salienta que alta variabilidade de propriedades físicas do solo, tais como o conteúdo de areia, argila e silte, bem como da densidade global, resultam em alta variabilidade nas características de retenção de água pelo solo. Dessa forma, torna-se importante o conhecimento de como se comportam estas propriedades, onde se pretende ter conhecimento e controle da dinâmica da água no solo. O solo funciona como suporte físico e reservatório de água para as plantas, além de, na maioria dos casos, ser o fornecedor dos principais nutrientes necessários à produção. As partículas do solo, arranjadas em grânulos e agregados, constituem um meio poroso com grande diversidade de forma e geometria, o que confere grande complexidade ao sub-sistema solo-água. Esse tipo de arranjo afeta a interação entre a água e o solo no sistema maior, solo-água-planta-atmosfera que, traduzida em termos de estado de energia da água na forma potencial, governa inúmeros processos, entre os quais o movimento da água, nutrientes e agroquímicos no solo e a absorção de água e nutrientes pela planta. $\mathrm{O}$ entendimento e descrição quantitativa do sub-sistema solo-água é, portanto, um passo fundamental para o entendimento e quantificação do 
sistema maior, onde ocorre a maioria dos processos envolvidos na produção de alimentos e fibras (Andrade et al., 1998).

Existem várias metodologias para se determinar o teor de água do solo, cada uma apresentando vantagens e desvantagens. Os métodos de determinação do teor de água no solo podem ser classificados como métodos diretos e indiretos. Como método direto, tem-se o gravimétrico que pode ser realizado extraindo a água da amostra com a utilização de uma estufa ou um forno de microondas. Os métodos diretos são destrutivos, o que impede a repetição da medição do teor de água no local. Os métodos indiretos são aqueles por meio dos quais torna-se possível determinar a quantidade de água presente no solo utilizando-se medidas de características relacionadas com o teor de água no solo. Esses métodos também apresentam algumas desvantagens. Uma delas é a necessidade da realização de uma curva de calibração que, na maioria das vezes, pode ser influenciada por características do solo e variações decorrentes do próprio meio ambiente. Pode-se identificar, no entanto, diversas vantagens, como a determinação do valor medido em um menor tempo e a possibilidade de verificação posterior, por não ser um método destrutivo (Gomide, 1998).

Para medição do teor de água no solo por métodos indiretos, os equipamentos atualmente disponíveis são sondas de nêutrons, sondas de raios gama, blocos porosos, tensiômetros, tomografia computadorizada de raios-X, método capacitivo, dissipação de calor numa matriz porosa rígida, membrana semipermeável e reflectometria no domínio de tempo (TDR - "time-domain reflectometry"). Recentemente, a técnica do TDR tem despertado interesse devido ao grande potencial na identificação do teor de água e da condutividade elétrica do solo (Gomide, 1998).

Métodos convencionalmente utilizados como os métodos gravimétricos, da sonda de nêutrons, e do TDR, requerem grande dispêndio de mão-de-obra (Hendrickx \& Wierenga, 1990). A relação entre teor de água e a condutividade elétrica do solo tem sido observada por diversos pesquisadores (Hendrickx et al., 1992; Rhoades et al., 1976).

Pesquisas recentes constataram que a medição da condutividade elétrica aparente ou condutividade elétrica do solo (CE), com o uso de sensores 
eletromagnéticos, tem o potencial de realizar medições rápidas do teor de água no solo (Sheets \& Hendrickx, 1995). Mankin et al. (1997) citam o trabalho de McNeil ${ }^{1}$ que enfatiza que a $\mathrm{CE}$ dos solos e das rochas depende da porosidade e do grau de enchimento dos poros com água.

Bobert et al. (2001), em pesquisa realizada em Wulfen, Alemanha, utilizaram um método que reunia as técnicas de modelagem digital do terreno, uma sonda de capacitância para monitorar o teor de água no solo e um sensor por indução eletromagnética para analisar a textura visando avaliar a distribuição do teor de água e poder tomar decisões sobre o correto gerenciamento da produção. O coeficiente de regressão entre os valores da condutividade elétrica e o parâmetro denominado de índice de molhamento topográfico (IMT) para os doze pontos de amostragem foi de 0,52. Os autores citam que como os valores de CE são dominados pela textura e teor de água no solo, o IMT pode ajudar a interpretar o mapa de CE. Uma combinação de ambos os métodos pode ser utilizada para melhorar a avaliação da distribuição espacial do teor de água no terreno quando for encontrada uma correlação entre o IMT e os valores de CE. Esse sistema pode ainda ser de grande ajuda na classificação de unidades de gerenciamento para a agricultura de precisão e, com ambos os métodos, o esforço na amostragem do solo pode ser reduzido.

\subsection{Condutividade elétrica do solo}

A condutividade elétrica é a habilidade que um material tem em transmitir ou conduzir corrente elétrica (Doerge, 2004; Lund et al., 1998; Kitchen et al., 1996). A CE é influenciada por diversos fatores do solo como a porosidade, concentração de eletrólitos dissolvidos, textura, quantidade e composição dos colóides, matéria orgânica e teor de água (Rhoades et al., 1976; Nadler \& Frenkel, 1980). Uma das utilidades da CE advém do fato de que a areia tem baixa condutividade e a argila tem alta condutividade (Lund et al., 1998).

Métodos de pesquisa geofísicos que medem diferenças nos valores de CE são usados, desde o início do século XX, para gerar mapas com características geológicas. Pesquisadores têm usado também a CE para medir ou estimar outras

\footnotetext{
${ }^{1}$ McNEIL, J.D. Electrical conductivity of soils and rocks. Mississauga: Geonics, 1980. (Tech. Note TN-5)
} 
propriedades químicas e físicas de solos não salinos, inclusive teor de água, teor de argila, capacidade de troca de cátions (CTC), cálcio $(\mathrm{Ca})$ e magnésio $(\mathrm{Mg})$ trocáveis, matéria orgânica (MO) e o comportamento de herbicidas no solo (Doerge, 2004).

O solo pode conduzir corrente elétrica através da água intersticial que contêm eletrólitos dissolvidos e através dos cátions trocáveis que residem perto da superfície de partículas de solo carregadas e são eletricamente móveis em vários níveis. Rhoades \& Corwin (1990) apresentam um modelo de condutividade elétrica que descreve a condutância através de três vias atuando em paralelo: (i) condutância através de camadas alternantes de partículas do solo e entre os limites de suas soluções, (ii) condutância através de soluções do solo contínuas, e (iii) condutância através ou entre superfícies de partículas do solo em contato direto entre elas. $\mathrm{Na}$ ausência de sais dissolvidos na água presente na segunda via, condutividade, textura e teor de água se correlacionam muito bem entre si. Fritz et al. (1998) confirmaram que a condutividade elétrica é influenciada pelo teor de água, sais, e pelo material de origem na formação do solo.

Para medição da condutividade elétrica dos solos são utilizados basicamente os métodos de indução eletromagnética e por contato direto (Rhoades \& Corwin, 1984). O método por indução eletromagnética consiste basicamente em um eletrodo de transmissão que é suspenso próximo à superfície do solo, o qual é energizado com corrente alternada em freqüência de áudio. Isso estabelece um campo magnético que induz corrente elétrica no solo gerando um segundo campo magnético a uma distância específica do eletrodo transmissor. O eletrodo receptor gera uma corrente alternada em resposta e proporcional àquela gerada pelo eletrodo transmissor, modificada pela condutividade elétrica do solo. Isso pode ser usado para obter uma leitura da condutividade aparente do solo que é linearmente proporcional à razão dos dois campos magnéticos (King et al., 2001). Esse método não tem contato com o solo e pode ser preferido se na área pesquisada o revolvimento do solo não é desejável por algum motivo, como, por exemplo, alguma forma de contaminação do solo. Também tem sido utilizado por geofísicos e geólogos há muitos anos, particularmente para ajudar na localização de depósitos de minerais metálicos (Brevik \& Fenton, 2000). Nos últimos vinte anos, cientistas do solo passaram a utilizar a indução eletromagnética em estudos aplicados à agricultura (Jaynes, 1996). Nessa aplicação 
os equipamentos de indução eletromagnética foram inicialmente utilizados para medição de sais solúveis e teor de água no solo. Outras aplicações agrícolas atualmente incluem a determinação das unidades de mapeamento dos solos, a estimativa da camada superficial em solos com acentuado gradiente textural, a profundidade de deposição de areia como conseqüência de enchentes de rios, a estimativa da degradação de herbicidas e da produtividade das culturas. Para cada uma dessas determinações uma relação precisa ser estabelecida entre a leitura do equipamento e a característica do solo em estudo. A partir do momento em que essa relação é estabelecida, as leituras e a conseqüente caracterização podem ser conseguidas rapidamente (Davis et al., 1997).

Fritz et al. (1998) descreveram um equipamento por indução eletromagnética que mede a condutividade elétrica do solo até uma profundidade de 0,12 $\mathrm{m}$ na configuração vertical e a uma profundidade até de $0,30 \mathrm{~m}$ na configuração horizontal. Um entrave do método é que o equipamento não pode sofrer interferência de metais, por isso o cuidado com o manuseio, no que diz respeito a vestimentas do operador, deve ser atentado e quando tracionado, o veículo onde é fixado também não pode conter nenhum metal. É um método de amostragem rápida para a coleta de informações sobre o solo e a distribuição espacial de algumas de suas propriedades (Domsch \& Giebel, 2001). Com o advento do Sistema de Posicionamento Global (GPS - "Global Position System”), o equipamento que mede a CE pode ser equipado com um receptor de GPS permitindo a geração de mapas de CE (Doerge, 2004).

O método por contato direto utiliza pelo menos quatro eletrodos que estão em contato direto com o solo; dois eletrodos injetam uma corrente no solo e os outros dois medem a voltagem resultante (Lund et al., 2000). São equipamentos de construção robusta, livre de interferências por metal, e não necessitam da calibração diária, fazendo com que o uso desse método fosse difundido na agricultura (Hartsock et al., 2000). Um modelo de equipamento utiliza um par de eletrodos, ligado a discos de corte, transmitindo uma corrente elétrica no solo, enquanto que os outros dois pares de eletrodos medem a diferença de potencial que ocorre no campo eletromagnético gerado no solo, devido à corrente elétrica aplicada. Os eletrodos necessitam penetrar no solo somente alguns centímetros. Os eletrodos de medição são configurados para medir essa diferença de potencial, simultaneamente, até a 
profundidade de $0,3 \mathrm{~m}$ e $0,9 \mathrm{~m}$, sendo a profundidade de leitura função do espaçamento entre os eletrodos. O sistema registra a condutividade medida e georreferencia utilizando um receptor de GPS. Quando utilizado com espaçamento entre as passadas de 15 a $20 \mathrm{~m}$ e velocidade de $12 \mathrm{~km} \cdot \mathrm{h}^{-1}$, o sistema produz entre 40 e 100 amostras por hectare (Christy \& Lund, 1998).

Pesquisas têm mostrado que o método por indução eletromagnética e o método por contato direto produzem resultados similares (Sudduth, et al., 1998). Em pesquisa realizada por Fritz et al. (1998) visando comparar as tecnologias da medição da CE por indução eletromagnética e por contato direto foi observada a relação da $\mathrm{CE}$ ao microrelevo do terreno, sendo que nas áreas de menor altitude a $\mathrm{CE}$ era maior se comparada com as áreas de maior altitude. Essa diferença foi atribuída aos efeitos combinados do acúmulo de água e sais nas áreas mais baixas. A CE por indução eletromagnética apresentou maiores valores de leituras nas áreas do terreno mais secas e valores menores nas áreas mais úmidas em relação às leituras do sensor de contato, indicando que esse último, em leituras rasas, tem uma sensibilidade ao teor de água diferente daquela CE por indução eletromagnética. Mesmo possuindo sensibilidade diferente, os autores afirmam que ambos os sistemas forneceram dados similares.

Solos excessivamente secos ou úmidos limitam a eficiência do método por indução eletromagnética. A proximidade de água subterrânea também influencia as leituras do equipamento (Jhonston ${ }^{2}$ citado por McKenzie et al., 1997).

Solos que contêm minerais com propriedades magnéticas como magnetita ou lepedocrocita, requerem calibração separada (Jhonston ${ }^{1}$ citado por McKenzie et al., 1997). Os efeitos do conteúdo de argila e da porosidade do solo na CE podem ser mostrados calibrando a CE obtida através do método de indução eletromagnética pela CE obtida pelo método de extratos de pasta saturada em solos com diferentes teores de argila (Bennett ${ }^{3}$ et al. citado por McKenzie et al., 1997).

A indução eletromagnética tem sido utilizada de diversas maneiras para mapear a salinidade do solo. O método mais simples é tomar uma série de leituras de salinidade com o medidor e utilizá-las para estabelecer limites para áreas de

\footnotetext{
${ }^{2}$ JOHNSTON, M.A. An evaluation of the four electrode and electromagnetic induction techniques of soil salinity measurement: Pietermeritzburg. Natal, University of Natal. Ph.D. dissertation, 191 p. 1994.

${ }^{3}$ BENNET, D.L.; GEORGE, R.J.; RYDER, A. Soil salinity assessment using the EM38: Field operation instruction and data interpretation: Western Australia Department of Agriculture, Miscellaneous Publication, 8 p. 1995.
} 
salinidade. O equipamento precisa ser calibrado de forma que as medidas de $\mathrm{CE}$ possam ser comparadas às medidas de CE por extração de pasta saturada para cada área amostrada (McKenzie et al., 1997).

Mudanças na temperatura influenciam a condutividade elétrica do solo e a condutividade da solução de uma maneira parecida (McNeil, 1986). Ocorre um aumento de aproximadamente $2 \%$ na condutividade para cada grau de aumento na temperatura. Já Brevik \& Fenton (2000) afirmam que a temperatura do solo tem influências desprezíveis sobre os valores de leituras dos equipamentos de CE se todas as leituras num mesmo campo foram feitas sob condições semelhantes no decorrer de um mesmo dia.

A CE como forma de monitorar propriedades diversas dos solos tem se mostrado eficiente em áreas onde uma das propriedades que afetam as leituras de $\mathrm{CE}$ é dominante sobre as outras e diferenças nas leituras podem ser relacionadas às variações da propriedade dominante (Doolittle et al. ${ }^{4}$ citado por Brevik \& Fenton, 2000). Bons resultados de medições de determinados fatores do solo foram obtidos com as tecnologias de monitoramento da $\mathrm{CE}$ em solos muito revolvidos no centro do estado de Iowa, EUA. Solos bastante revolvidos possuem a tendência de apresentarem alta variabilidade espacial (Brevik \& Fenton, 2000).

\subsection{Características físico-químicas do solo e condutividade elétrica}

A resposta da $\mathrm{CE}$ à presença de argila tem sido usada para estimar a profundidade do horizonte superficial em relação a uma camada sub-superficial acentuadamente argilosa (Doolittle et al., 1994; Jaynes, 1996). Pesquisas também suportam a correlação entre a CE e a capacidade de troca de cátions (CTC) devido à relação da segunda com a argila (McBride et al., 1990).

Depois da grande inundação ocorrida no meio-oeste americano, em 1993, foi conduzida uma pesquisa associando a indução eletromagnética com a sondagem laboratorial da $\mathrm{CE}$, levando em consideração a localização geográfica dos pontos amostrados visando avaliar a quantidade de areia depositada nas áreas de quatro fazendas adjacentes ao leito do rio Missouri. Uma forte relação entre as leituras dos

${ }^{4}$ DOOLITTLE, J.A.; MURPHY, R.; PARKS, G.; WARNER, J. Electromagnetic induction investigation of a soil delineation in Reno Country, Kansas, Soil Survey Horizone, v. 37, p. 11-20. 1996. 
equipamentos eletromagnéticos e as medidas de profundidade de deposição de areia utilizando métodos convencionais de tradagem foi encontrada, com valores do coeficiente de regressão entre 0,73 e 0,94 (Kitchen et al., 1996).

A textura do solo pode variar significativamente dentro da mesma área de produção, mas, normalmente, é manejada como homogênea (Machado et al., 2003). A amostragem do solo pode ser reduzida através da leitura da $\mathrm{CE}$, quando essa possui alta relação com a textura, sendo convertida em parâmetros de textura do solo. Pesquisa realizada na região de Brandenburgo, Alemanha, demonstrou que a influência do conteúdo de argila nas leituras de CE, na capacidade de campo, podem ser consideradas de $59 \%$ do valor total da CE para solos da região, desde que os horizontes do solo não sejam influenciados pela água. Se o conteúdo de silte também for levado em consideração, a relação entre a $\mathrm{CE}$ e a textura tornam-se ainda mais evidentes, podendo chegar a $69 \%$ do valor total da CE. Solos gleizados com horizontes influenciados pela água devem ser considerados em separado. A relação entre a CE e a argila é suplantada pelo teor de água nos horizontes saturados pela água (Domsch \& Giebel, 2001).

A característica do solo que muitas vezes é a determinante na variação da produtividade numa mesma lavoura é sua habilidade em armazenar e fornecer água para o crescimento das plantas. Infelizmente, a medição do teor de água em grandes áreas é de difícil avaliação. A correlação entre a $\mathrm{CE}$ e a produtividade ainda é um tema recente de pesquisa, mas os resultados iniciais são promissores, especialmente quando a produtividade é influenciada pela capacidade de retenção de água (Lund et at., 1998).

A condutividade elétrica pode servir como uma representação das propriedades físicas do solo como a matéria orgânica (Jaynes, et al., 1994), conteúdo de argila (Williams \& Hoey, 1987), e capacidade de troca de cátions (McBride, et al., 1990). Estas propriedades têm um significante efeito na capacidade de armazenamento de água e nutrientes, os quais têm maiores influências na produtividade (Jaynes, 1996). A relação entre CE e produtividade tem sido apresentada e quantificada por outros autores (Kitchen \& Sudduth, 1996; Fleming, et al., 1998). Trabalhos realizados nos Estados Unidos (Kitchen et al., 1996) mostraram 
que medições da CE ajudaram a explicar a variação da produtividade, no entanto a relação entre $\mathrm{CE}$ e produtividade não é simplesmente linear.

Devido aos fatores que controlam a CE dos solos (conteúdo de argila, sais solúveis, teor de água e temperatura) não é surpresa que muitos dos estudos iniciais utilizando as técnicas de indução eletromagnética envolvessem a identificação e delineamento de solos salinos (Williams \& Hoey, 1987; Brevik \& Fenton 2000). Brevik \& Fenton (2000) citam que esses estudos continuam a receber atenção considerável.

Em pesquisa realizada em Falsalabad, Paquistão, em campos irrigados, a CE foi medida utilizando um equipamento por indução eletromagnética. A análise geoestatística dos dados indicou que a salinidade dos campos era principalmente determinada pelo manejo da irrigação. Diferenças significativas de salinidade foram encontradas entre áreas abandonadas, em pousio e cultivadas, mas não entre campos com diferentes culturas (Hendrickx et al., 1992).

\subsection{Estatística descritiva, dependência espacial e geoestatística}

Obtidos os valores de alguma característica de uma população, segundo uma amostragem, deve-se descrever o comportamento dos mesmos, de acordo com parâmetros que expressam medidas de posição, dispersão, forma, etc. Esse estudo compreende a estatística descritiva (Doria Filho, 1999).

Uma das avaliações da dispersão dos dados pode ser feita pelo coeficiente de variação $(\mathrm{CV})$ que é a relação entre o desvio padrão e a média do conjunto de dados e expressa o grau de variabilidade do atributo, não refletindo sua forma (Grossi Sad, 1986). A utilização do CV na avaliação da variabilidade dos dados tem a vantagem de permitir a comparação entre propriedades distintas, pois é uma medida adimensional, apresentando o mesmo valor independentemente das unidades utilizadas nas medidas (Warrick \& Nielsen, 1980; Dourado Neto, 1989; Machado, 1994).

Mesmo em uma área de solo homogêneo, a mensuração de uma propriedade do solo em alguns pontos pode revelar grandes variações de valores, pois o solo é produto da ação de diversos fatores de formação e varia continuamente na superfície. 
Uma propriedade do solo é uma variável com continuidade espacial (Burgess e Webster, 1980) e, como tal, constitui em uma população infinita em uma determinada área. Para se inferir sobre as características dessa população, ou seja, para descrever a propriedade na área, torna-se necessária uma abordagem estatística, onde se procura inferir, a partir de valores amostrais, sobre os parâmetros que caracterizam a sua distribuição de freqüência.

Os métodos clássicos da estatística admitem a normalidade e a independência dos dados. Em experimentação agronômica, a variação devida ao solo pode ser superada por meio da casualização e da repetição, além do controle local, sendo os resultados analisados por meio de análise de variância. A conveniência desses métodos fez com que os estudos da variabilidade das propriedades dos solos não despertassem maiores interesses, até um momento relativamente recente, quando então começaram a ser retomados (Gonçalves, 2000). Beckett \& Webster (1971) ressaltam a necessidade de se dar uma maior atenção ao assunto.

A motivação para estudos mais minuciosos da variabilidade de propriedades do solo revelou limitações das ferramentas estatísticas utilizadas até então para a análise dos dados (Gonçalves, 2000).

Gonçalves et al. (1998) mostram que uma forte correlação espacial entre variáveis pode não ser descrita pela estatística, o que torna importante o uso da geoestatística (Vieira et al., 1983). No entanto, conforme estabelecido por Hamlett et al. (1986) e discutido por Libardi et al. (1986), a descrição minuciosa dos dados deve preceder qualquer análise geoestatística.

Webster \& Oliver (1990) afirmam que muitas propriedades do solo variam continuamente no espaço e, conseqüentemente, os valores em locais mais próximos entre si tendem a ser mais semelhantes que aqueles tomados mais distantes entre si, até uma distância limite, correspondente ao domínio destas propriedades. Caso isto ocorra, os dados não podem ser tratados como independentes e um tratamento estatístico mais adequado é necessário.

Para descrição de variáveis dependentes da sua localização geográfica, a geoestatística fornece algumas ferramentas como a função de correlação, a covariância e o semivariograma para quantificação da relação da variável em estudo com sua posição no terreno. 
O semivariograma experimental pode assumir diversas formas em função dos dados e da distância entre as amostragens. O semivariograma começa, normalmente, com um valor baixo, denominado efeito pepita $\left(\mathrm{C}_{0}\right)$ e cresce à medida que aumentam as distâncias entre os pares de pontos das amostras, até uma distância denominada de alcance (a), que determina a distância até a qual a propriedade se apresenta espacialmente dependente. A partir desta distância, os dados podem ser considerados independentes. Para distâncias maiores que o alcance, o semivariograma tende a se estabilizar em torno de um valor denominado patamar $\left(\mathrm{C}_{1}\right)$.

A partir da identificação do padrão de variabilidade espacial de uma variável no terreno é possível gerar estimativas de valores desconhecidos da mesma, próximos a valores conhecidos, permitindo a geração de mapas de atributos espacialmente dependentes (Isaaks \& Srivastava, 1989). Segundo King et al. (2001), a grande maioria das aplicações dos conceitos da geoestatística em ciências dos solos, utilizam semivariogramas gerados pelo estimador de Matheron. 


\section{MATERIAL E MÉTODOS}

Os dados foram coletados em duas áreas experimentais cujas descrições são apresentadas na Tabela 1.

Tabela 1. Descrição das áreas experimentais do projeto

\begin{tabular}{ccccccc}
\hline Área & $\begin{array}{c}\text { Nome da } \\
\text { Propriedade }\end{array}$ & Município/UF & $\begin{array}{c}\text { Tamanho } \\
(\mathrm{ha})\end{array}$ & $\begin{array}{c}\text { Altitude } \\
(\mathrm{m})\end{array}$ & Clima & Sistema \\
\hline 1 & Fazenda Sol & Tibagi/PR & 18,90 & 843 & Temperado & $\begin{array}{c}\text { Semeadura } \\
\text { Direta }\end{array}$ \\
2 & $\begin{array}{c}\text { Agropecuária } \\
\text { Dois Irmãos }\end{array}$ & $\begin{array}{c}\text { Campos Novos } \\
\text { Paulista/SP }\end{array}$ & 22,19 & 450 & $\begin{array}{c}\text { Subtropical } \\
\text { úmido }\end{array}$ & $\begin{array}{c}\text { Semeadura } \\
\text { Direta }\end{array}$ \\
\hline
\end{tabular}

Para a mensuração da CE nas áreas experimentais foi utilizado o equipamento que mede a CE pelo método do contato direto, Veris $3100^{\circledR}$ (Figura 1a). Utiliza como eletrodos, discos de corte lisos que cortam os resíduos vegetais e penetram no solo. Esse equipamento possui seis discos de corte, devidamente espaçados para promover leituras de $\mathrm{CE}$ nas profundidades de 0 a $0,3 \mathrm{~m}\left(\mathrm{CE}_{30}\right)$ e 0 a $0,9 \mathrm{~m}\left(\mathrm{CE}_{90}\right)$, onde dois discos são utilizados para emitir corrente elétrica alternada no solo e quatro discos, um par para cada profundidade, medem a voltagem resultante (Figura 1b). Apresenta largura de 2,35 m, comprimento de 2,44 m e altura de $0,89 \mathrm{~m}$ e, segundo seu fabricante, requer uma potência de $15 \mathrm{~kW}$ a $20 \mathrm{~kW}$ para ser tracionado, dependendo da velocidade, da topografia e das condições do solo. A velocidade de operação recomendada é de até $7 \mathrm{~m} . \mathrm{s}^{-1}$. Para auxiliar a penetração e aumentar o contato com o solo são utilizados lastros.

$\mathrm{O}$ equipamento possui um coletor de dados próprio (Figura 1c) com um microprocessador 386SX e capacidade de leitura contínua de dados obtidos no campo, de até 26 horas. Realiza a gravação dos valores de CE para as duas 
profundidades, simultaneamente, num intervalo mínimo de 1s. Os valores de CE são expressos em mS.m $\mathrm{m}^{-1}$. O sistema georreferencia as medições de CE utilizando um receptor de GPS e armazena os dados em formato digital de texto ASCII.

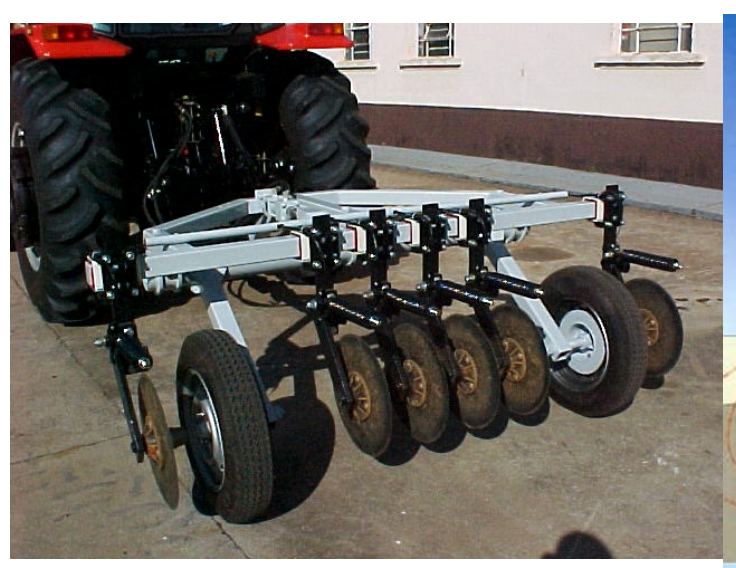

a

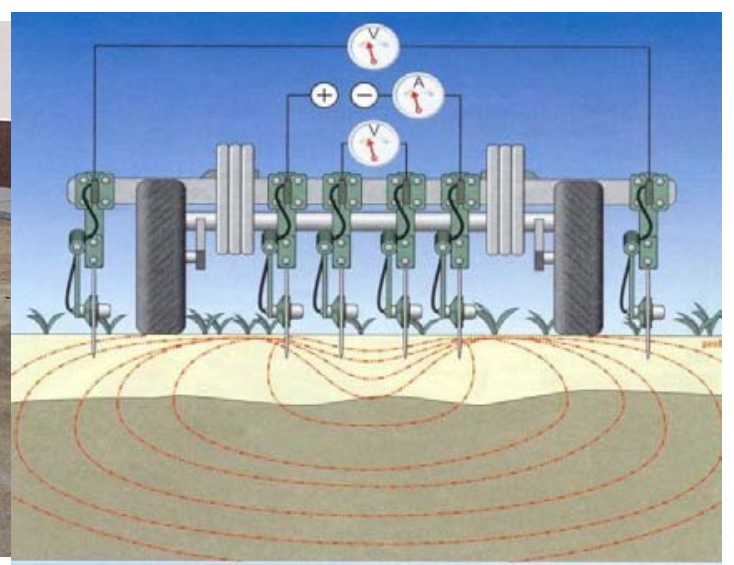

b

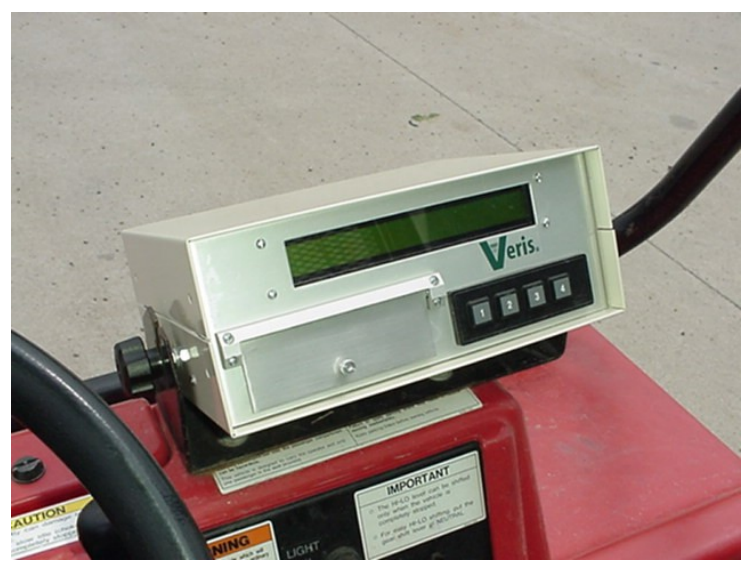

C

Figura 1 - Equipamento de CE utilizado no estudo (a), esquema de funcionamento do equipamento (fonte: manual do fabricante) (b) e coletor de dados contendo também o circuito do sensor (c)

Antes do início das atividades de aquisição dos dados, o equipamento passava por testes indicados pelo fabricante para a certificação de isolamento dos eletrodos e do seu correto funcionamento. Os dados de CE foram coletados duas vezes em cada área experimental.

$\mathrm{Na}$ área 1, as mensurações foram realizadas nos dias 24 de outubro de 2003 e 22 de junho 2004, utilizando um trator marca Massey Ferguson, modelo 50x para 
tracionar o equipamento, com espaçamento entre passadas paralelas de aproximadamente $10 \mathrm{~m}$. Na primeira medição o coletor de dados estava conectado a um receptor de sinal do GPS da marca OmniSTAR (Fugro ${ }^{\circledR}$ ), e na segunda a um receptor marca SATLOC ${ }^{\circledR}$, ambos sem sinal de correção diferencial

$\mathrm{Na}$ área 2 as medições ocorreram nos dias 15 de outubro de 2003 e 30 de outubro de 2004. Na primeira medição o equipamento foi tracionado por um trator marca Valmet, modelo 75, com espaçamento entre passadas paralelas de aproximadamente $4 \mathrm{~m}$. O receptor de sinal do GPS utilizado era da marca OmniSTAR (Fugro ${ }^{\circledR}$ ) com sinal de correção diferencial via satélite geoestacionário, da mesma marca. Na segunda medição o sensor foi tracionado por um trator marca New Holland, modelo TL75E, com espaçamento entre passadas paralelas de aproximadamente $10 \mathrm{~m}$, com um receptor de sinal do GPS da marca SATLOC ${ }^{\circledR}$. A diferença nas densidades amostrais da CE nesta área, na primeira (4 m) e na segunda medição $(10 \mathrm{~m})$ foi intencional, visando utilizar os dados de $\mathrm{CE}$ da primeira medição em outro estudo, sem que, com isso, prejudique a qualidade desse trabalho.

As amostras do teor de água foram retiradas na mesma ocasião em que foi monitorada a $\mathrm{CE}$, na profundidade de 0 a $0,3 \mathrm{~m}$. Na área 1 a densidade amostral foi de 4,2 amostras por hectare, enquanto que na área 2 a densidade foi de 3,0 amostras por hectare no ano de 2003 e 1,5 amostras por hectare no ano de 2004. Essa redução na densidade amostral foi estabelecida com base na análise dos parâmetros do semivariograma das amostras do teor de água do ano de 2003.

Todas as amostras coletadas foram colocadas em cápsulas de alumínio, vedadas com fita crepe e levadas ao Laboratório de Implantação de Culturas do Departamento de Engenharia Rural da Escola Superior de Agricultura "Luiz de Queiroz”, Piracicaba, SP, para pesagem. Após a secagem em estufa a $105^{\circ} \mathrm{C}$ por 24 horas, realizou-se nova pesagem e determinou-se o teor de água no solo pelo método gravimétrico (EMBRAPA, 1999).

Segundo Babalola (1978) a alta variabilidade de propriedades físicas do solo, tais como o conteúdo de areia, argila e silte, resultam em alta variabilidade nas características de retenção de água pelo solo. Uma das utilidades da CE advém do fato de que a areia tem baixa condutividade e a argila tem alta condutividade (Lund et al., 1998). Por existir relações diretas entre teor de água e argila, também foram 
coletadas amostras de solo na área 1, ano 2003, para análise textural do solo, determinada pelo método de Bouyoucos (Gee \& Bauder, 1986), no laboratório da Fundação ABC, localizado na cidade de Castro, PR. As amostras foram coletadas com uma densidade amostral de 2,1 amostras.ha ${ }^{-1}$, na profundidade de 0 a $0,2 \mathrm{~m}$. Na área 2, foram utilizados as informações de textura já existentes, também determinadas pelo método de Bouyoucos (Gee \& Bauder, 1986), coletadas na profundidade de 0 a $0,2 \mathrm{~m}$, com uma densidade de 4,1 amostras.ha $^{-1}$, no ano 2000.

Foram utilizadas informações das precipitações ocorridas no intervalo de 30 dias antecedentes a coleta dos dados. Para a área 1 essas informações foram cedidas pela Fundação $\mathrm{ABC}$ e, para a área 2, pela própria fazenda.

Antes da análise estatística descritiva, os dados de CE coletados pelo equipamento foram classificados em ordem decrescente, no programa computacional Microsoft ${ }^{\circledR}$ Excel 2002, para verificação e avaliação dos valores negativos. Segundo o manual do sensor, cada valor negativo indica alguma anormalidade com a coleta dos dados naquele local específico, podendo, numa única leitura, ocorrer combinações dessas anormalidades.

A etapa da estatística descritiva foi realizada utilizando-se o programa computacional STATISTICA 6.0 (Statsoft Inc. ${ }^{\circledR}$ ). Para caracterizar o comportamento dos dados calculou-se até os momentos estatísticos de ordem quatro, que também expressam o formato da distribuição, através dos coeficientes de assimetria e curtose.

Para os valores de CE e teor de água foram estabelecidas classificações segundo a metodologia proposta por Tukey (1977). As amostras cujos valores são menores do que o quartil inferior menos 1,5 vezes a amplitude interquartílica e maiores do que o quartil superior mais 1,5 vezes a amplitude interquartílica, são consideradas como extremos, podendo ser candidatas à exclusão, se confirmadas pela análise exploratória.

O coeficiente de variação foi calculado para verificar a dispersão dos dados em relação à média de cada variável, servindo de comparação da dispersão entre diferentes variáveis. Adotou-se a classificação proposta por Warrick \& Nielsen (1980) para qualificar a variação de cada variável em função do seu CV. Esta classificação considera os valores do CV entre $12 \%$ e $60 \%$ como de média 
variabilidade e os valores abaixo e acima desse intervalo como de baixa e alta variabilidade, respectivamente.

A verificação do ajuste dos dados à distribuição normal foi feita através dos coeficientes de assimetria e curtose e pelo teste de Kolmogorov-Smirnov (K-S) a diferentes níveis de probabilidade. Os coeficientes de assimetria e curtose indicam a proximidade da distribuição de freqüências dos dados e da distribuição normal, cujos valores são zero e três. No teste de K-S a hipótese nula, de que a distribuição de uma variável era normal, foi rejeitada sempre que $\mathrm{P} \leq 10$.

Numa segunda etapa da análise estatística, buscou-se a confirmação ou não da validade dessas medidas de posição ou dispersão, o que foi feito utilizando-se algumas das técnicas da análise exploratória de dados, aliada a uma descrição espacial dos conjuntos de variáveis obtidas (Isaaks \& Srivastava, 1989). Apesar da qualidade da informação fornecida pela estatística descritiva, essa ignora a posição espacial de cada valor da variável. A visualização foi realizada para as variáveis de $\mathrm{CE}$, teor de água e textura, utilizando o sistema de informação geográfica (SIG) dedicado à agricultura de precisão SSToolBox 3.4 (SST Development Group, Inc ${ }^{\circledR}$ ). Esta etapa consiste na espacialização dos valores candidatos a discrepantes. Se os valores candidatos a discrepantes estiverem localizados de forma aglomerada ou em regiões conhecidamente diferenciadas, esses não são considerados discrepantes, mas, se não apresentaram nenhum indício de que fazem parte de uma região diferenciada, serão considerados discrepantes e removidos.

Para a realização da análise de dependência espacial das variáveis de $\mathrm{CE}$, teor de água e argila, utilizou-se as ferramentas derivadas da teoria das variáveis regionalizadas, onde $\mathrm{Z}(\mathrm{x})$ pode ser definida como uma variável aleatória que assume diferentes valores $Z_{i}$ em função da posição x dentro de uma certa região, uni, bi ou tridimensional, com certa aparência de continuidade (Souza, 1999). O conjunto de variáveis $\mathrm{Z}(\mathrm{x})$ medidas em toda a área pode ser considerado uma função aleatória $\mathrm{Z}(\mathrm{x})$, uma vez que são variáveis aleatórias, regionalizadas e considera-se que a dependência entre elas é regida por algum mecanismo probabilístico (Isaaks \& Srivastava, 1989).

Utilizando o programa computacional VESPER 1.6 (Minasny et al., 2002) foi realizada a construção dos semivariogramas experimentais para as distribuições da 
$\mathrm{CE}$, teor de água e argila nas duas áreas experimentais. Foi utilizado o estimador clássico do semivariograma, ou método dos momentos, ou estimador de Matheron.

O passo seguinte foi ajustar o modelo ao semivariograma experimental obtido. Para a escolha dos modelos e dos parâmetros, mais adequados para cada caso, foi utilizado o critério de minimização da soma dos erros quadrados.

Após a análise de dependência espacial de todas as variáveis foram realizadas estimativas em locais não amostrados, com o intuito de gerar mapas de superfície. Para a digitalização e visualização utilizou-se dos recursos da krigagem ordinária por blocos realizada pelo programa computacional VESPER 1.6 (Minasny et al., 2002). $\mathrm{O}$ tamanho da célula do mapa gerado foi estabelecido em $10 \mathrm{~m}$. O número de amostras a serem utilizadas na estimativa de cada bloco foi estabelecido no intervalo entre o mínimo de 4 e o máximo de 100. Para as variáveis teor de água e argila o raio de busca da krigagem foi estabelecido como sendo igual ao alcance da continuidade espacial da respectiva variável. Já para a variável CE o raio de busca foi determinado pelo programa computacional VESPER 1.6 (Minasny et al., 2002), determinado em função da densidade amostral.

Para avaliar a relação de dependência das variáveis foi utilizada a regressão polinomial. Procura-se descrever por um modelo matemático o quanto da variação da variável dependente pode ser explicada pela variável independente (Doria Filho, 1999). Foram utilizados dois conjuntos de dados na obtenção dos coeficientes de determinação $\left(r^{2}\right)$ dessa dependência. $O$ primeiro conjunto utilizou valores interpolados da $\mathrm{CE}$ e do teor de água na determinação da relação de dependência. $\mathrm{O}$ segundo conjunto utilizou um valor médio dos valores da $\mathrm{CE}$ compreendidos num raio de $15 \mathrm{~m}$ do ponto amostral do teor de água, através do programa computacional SSToolBox 3.4 (SST Development Group, Inc ${ }^{\circledR}$ ), com isso foi possível obter a relação de dependência da $\mathrm{CE}$ com o teor de água no solo na região onde foi amostrado o teor de água com procedimento semelhante ao utilizado por Molin et al. (2001). 


\section{RESULTADOS E DISCUSSÃO}

Antes da análise estatística descritiva dos dados de CE foram removidas as amostras que apresentavam leituras de CE negativas (Tabela 2).

Tabela 2. Total de amostras registradas no coletor de dados e amostras removidas por apresentarem leituras negativas

\begin{tabular}{ccccc}
\hline Área & Ano & $\begin{array}{c}\text { Total de amostras } \\
\text { coletadas }\end{array}$ & \multicolumn{2}{c}{ Amostras removidas* } \\
$\mathrm{CE}_{30}$ & $\mathrm{CE}_{90}$ \\
\hline 1 & 2003 & 5.004 & 1 & 2.450 \\
1 & 2004 & 8.472 & 0 & 223 \\
2 & 2003 & 10.402 & 0 & 0 \\
2 & 2004 & 8.734 & 1 & 1.396 \\
\hline
\end{tabular}

* Valores negativos de CE.

Uma quantidade elevada de valores negativos foi observada na $\mathrm{CE}_{90}$, especialmente no primeiro monitoramento da área 1 e no segundo monitoramento da área 2. Um quinto dos valores negativos na profundidade de 0 a $0,9 \mathrm{~m}$ da área 1 correspondem à falta de contato dos discos sensores com o solo, possivelmente pela irregularidade da superfície do terreno, fazendo com que os discos externos que medem nesta profundidade não entrassem em contato com o solo. $\mathrm{O}$ restante dos valores negativos correspondem à medida de voltagem acima do máximo. Na área 2 todos os pontos negativos foram decorrentes da combinação de voltagem abaixo do mínimo e medida de voltagem acima do máximo, segundo a classificação dos números negativos descrita no manual.

Os dados da CE nas duas áreas experimentais foram submetidos à análise estatística descritiva e, segundo a metodologia proposta por Tukey (1977), foram calculados os valores dos limites inferior e superior desta distribuição. Esses valores, 
após análise exploratória, são passíveis de serem excluídos do conjunto de dados originais por serem considerados discrepantes. A quantidade de valores da CE abaixo do limite inferior e acima do limite superior são apresentados na Tabela 3.

Tabela 3. Quantidade de prováveis valores discrepantes da $\mathrm{CE}$ nas duas áreas experimentais

Quantidade de prováveis valores discrepantes da

\begin{tabular}{|c|c|c|c|c|}
\hline \multirow{3}{*}{ Área } & \multirow{3}{*}{ Ano } & \multirow{3}{*}{ Profundidade } & \multicolumn{2}{|c|}{$\mathrm{CE}$} \\
\hline & & & Abaixo do limite & Acima do limite \\
\hline & & & inferior & superior \\
\hline \multirow{4}{*}{1} & \multirow{2}{*}{2003} & $0-0,3 \mathrm{~m}$ & 0 & 49 \\
\hline & & $0-0,9 \mathrm{~m}$ & 0 & 9 \\
\hline & \multirow{2}{*}{2004} & $0-0,3 \mathrm{~m}$ & 0 & 72 \\
\hline & & $0-0,9 \mathrm{~m}$ & 0 & 72 \\
\hline \multirow{4}{*}{2} & \multirow{2}{*}{2003} & $0-0,3 \mathrm{~m}$ & 13 & 190 \\
\hline & & $0-0,9 \mathrm{~m}$ & 8 & 513 \\
\hline & \multirow{2}{*}{2004} & $0-0,3 \mathrm{~m}$ & 43 & 159 \\
\hline & & $0-0,9 \mathrm{~m}$ & 0 & 340 \\
\hline
\end{tabular}

A decisão de manter ou excluir esses dados foi tomada após a realização da etapa da análise exploratória dos dados, onde esses valores de $\mathrm{CE}$, candidatos a discrepantes de cada distribuição, foram visualizados espacialmente.

Na área 1, no ano de 2003 e 2004, as amostras classificadas como candidatas a discrepantes nas duas profundidades não foram excluídas, pois estavam localizadas em regiões onde o teor de água e a argila possuíam valores mais elevados (Figura 2). $\mathrm{Na}$ área 2, ano 2003, optou-se por excluir todos os valores da $\mathrm{CE}_{30}$ e $\mathrm{CE}_{90}$ que estavam abaixo do limite inferior, por não apresentarem nenhuma indicação de regiões diferenciadas, e um valor acima do limite superior na $\mathrm{CE}_{30}$ por estar muito elevado. Já o restante dos valores acima do limite superior foram mantidos, pois a região onde há maior concentração faz divisa com a estrada da fazenda, sendo essa região do talhão usada para manobras, demonstrações de campo, etc., além de haver acúmulo de água na parte mais baixa. Nessa mesma área, no ano 2004, todos os 
valores candidatos a discrepante foram excluídos, por não apresentarem indícios de agrupamentos ou regiões diferenciadas (Figura 3). 


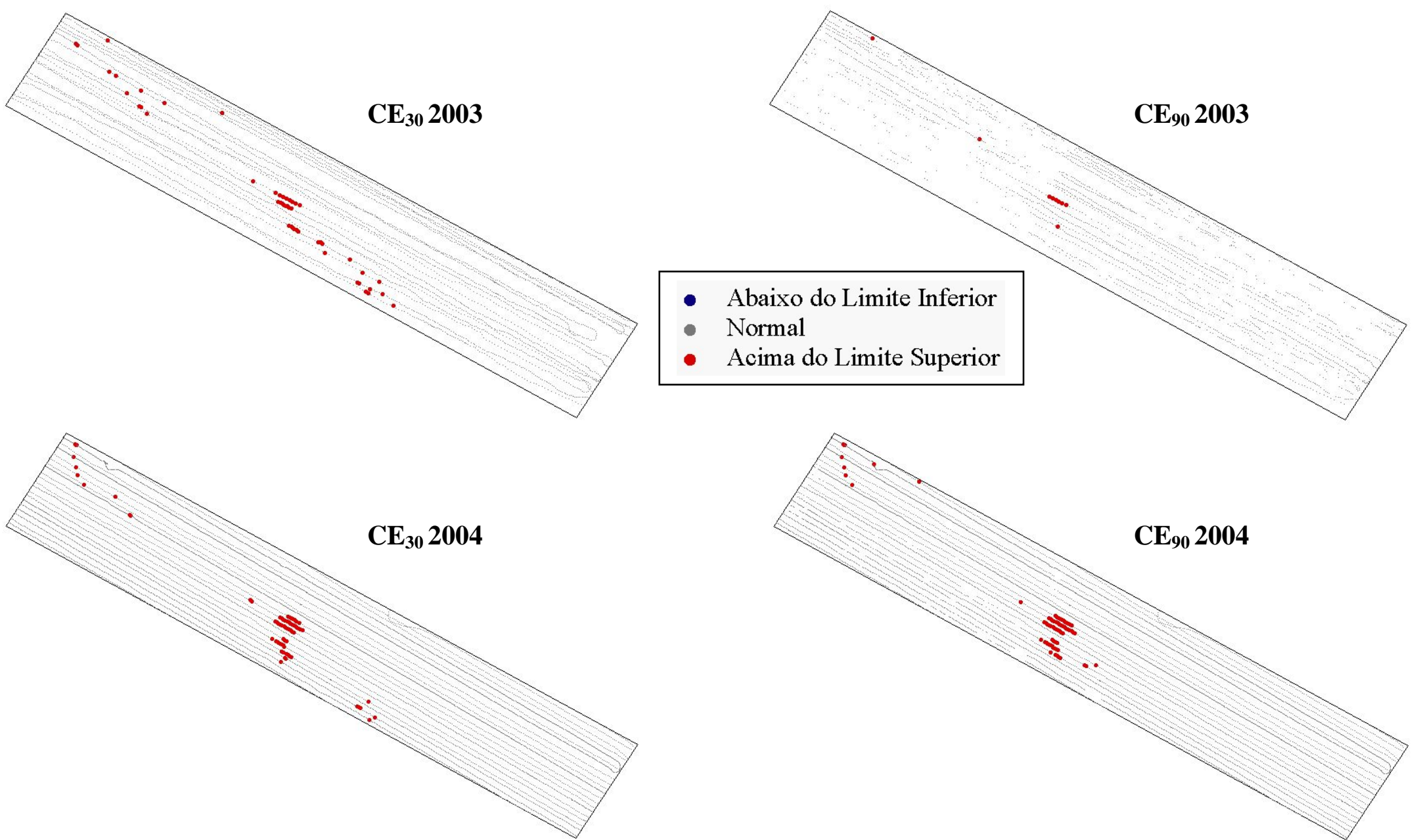

Figura 2 - Visualização dos pontos amostrais da CE na área 1 classificados segundo Tukey (1977) 


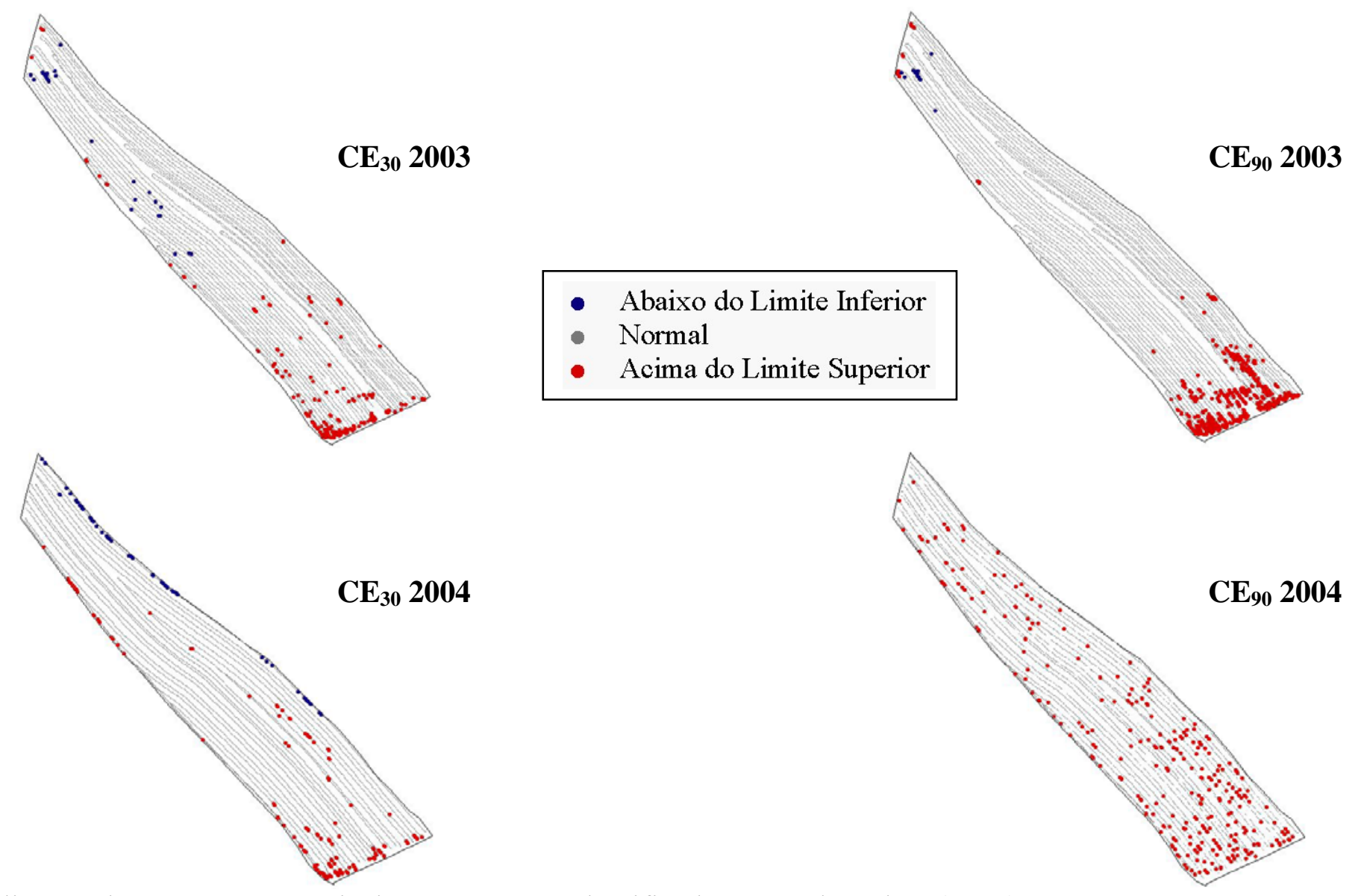

Figura 3 - Visualização dos pontos amostrais da CE na área 1 classificados segundo Tukey (1977) 
$\mathrm{Na}$ Tabela 4, são apresentadas as análises estatísticas descritivas para valores da $\mathrm{CE}_{30}$ e $\mathrm{CE}_{90}$ nas duas áreas experimentais após a análise exploratória.

Tabela 4. Estatística descritiva para os valores de CE $\left(\mathrm{mS}^{-1} \mathrm{~m}^{-1}\right)$ nas leituras de 0 a $0,3 \mathrm{~m}$ e 0 a $0,9 \mathrm{~m}$ de profundidade após a análise exploratória

\begin{tabular}{|c|c|c|c|c|c|c|c|c|}
\hline \multirow{4}{*}{ Estatística } & \multicolumn{8}{|c|}{$\mathrm{CE}\left(\mathrm{mS} \cdot \mathrm{m}^{-1}\right)$} \\
\hline & \multicolumn{4}{|c|}{ Área 1} & \multicolumn{4}{|c|}{ Área 2} \\
\hline & \multicolumn{2}{|c|}{2003} & \multicolumn{2}{|c|}{2004} & \multicolumn{2}{|c|}{2003} & \multicolumn{2}{|c|}{2004} \\
\hline & $\mathrm{CE}_{30}$ & $\mathrm{CE}_{90}$ & $\mathrm{CE}_{30}$ & $\mathrm{CE}_{90}$ & $\mathrm{CE}_{30}$ & $\mathrm{CE}_{90}$ & $\mathrm{CE}_{30}$ & $\mathrm{CE}_{90}$ \\
\hline $\mathrm{N}^{\mathrm{o}}$ amostras & 5.003 & 2.554 & 8.472 & 8.249 & 10.388 & 10.394 & 8529 & 6996 \\
\hline Mínimo & 1,0 & 0,8 & 0,6 & 0,6 & 2,9 & 1,8 & 3,9 & 1,8 \\
\hline Máximo & 12,9 & 20,9 & 13,1 & 9,8 & 16,6 & 12,6 & 12,7 & 24,3 \\
\hline Média & 4,1 & 2,2 & 3,0 & 1,8 & 6,2 & 3,7 & 8,3 & 11,2 \\
\hline Mediana & 3,6 & 1,9 & 2,4 & 1,6 & 6,1 & 3,5 & 8,2 & 10,3 \\
\hline Desvio padrão & 1,8 & 0,9 & 1,7 & 0,9 & 1,3 & 0,9 & 1,7 & 4,4 \\
\hline C.V. $(\%)$ & 43,5 & 41,8 & 57,4 & 47,2 & 21,5 & 25,2 & 20,2 & 39,2 \\
\hline Assimetria & 0,86 & 4,87 & 1,08 & 1,63 & 0,70 & 1,77 & 0,16 & 0,77 \\
\hline Curtose & 0,28 & 2,39 & 0,92 & 6,54 & 1,70 & 5,69 & $-0,12$ & 0,08 \\
\hline $\mathrm{D}$ & $0,12 *$ & $0,12 *$ & $0,15^{*}$ & $0,15^{*}$ & $0,05^{*}$ & $0,14 *$ & $0,04 *$ & $0,09 *$ \\
\hline
\end{tabular}

* - distribuição normal a 1\% de probabilidade (Campos, 1976).

Observando o resumo estatístico apresentado na Tabela 4 , os valores de $\mathrm{CE}_{30}$ se mantiveram, na maioria dos casos, maiores em relação a $\mathrm{CE}_{90}$, como também observado por Castro (2004) e Buchleiter \& Farahani (2002).

$\mathrm{Na}$ área 2, no ano de 2004, os valores da $\mathrm{CE}_{90}$ foram maiores em relação a $\mathrm{CE}_{30}$, surgindo a hipótese de que essa foi influenciada pelo teor de água. Esta hipótese não pode ser confirmada em função das amostras de solo para o teor de água e argila não terem sido coletadas nesta profundidade. Porém diversos autores observaram a relação da CE com o teor de água e argila (Hendrickx et al., 1992; Rhoades et al., 1976; Doolittle et al., 1994; Jaynes, 1996), e levando em consideração que a textura do solo não varia em curtos espaços de tempo (Domsch \& Giebel, 2001), o teor de água em maiores profundidades pode estar influenciando a $\mathrm{CE}_{90}$. 
Os registros das precipitações ocorridas nos anos de 2003 e 2004, dos 30 dias antecedentes a coleta dos dados, são demonstrados para a área 1 (Figura 4a) e para a área 2 (Figura 4b).
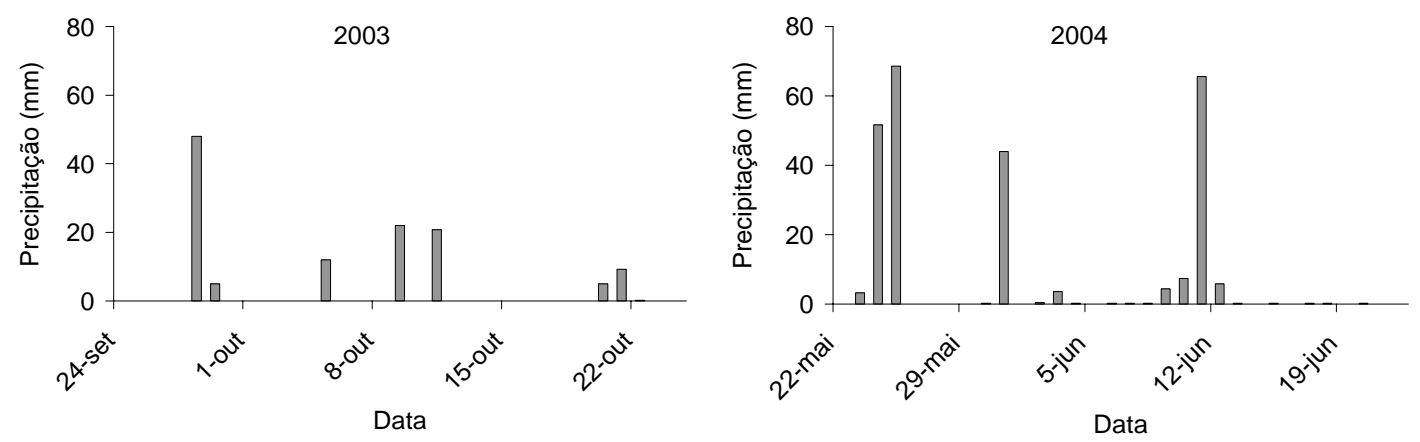

a
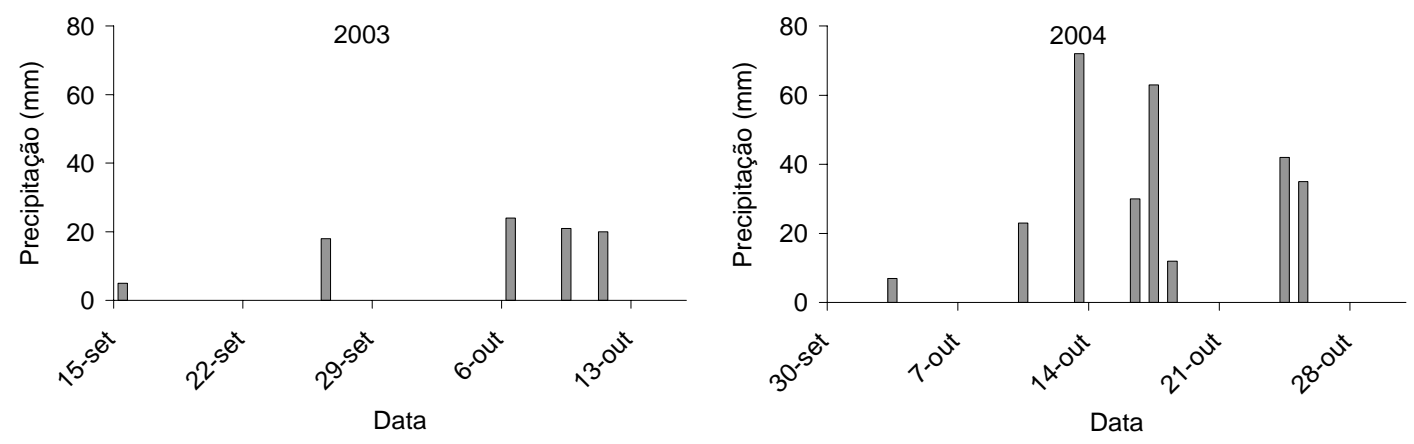

b

Figura 4 - Histórico de precipitação dos anos de 2003 e 2004, com os 30 dias antecedentes a coleta de dados, na área 1 (a) e na área 2 (b)

Observando a Figura 4, a hipótese de que o teor de água estaria influenciando, com valores mais elevados, a $\mathrm{CE}_{90}$ do que na profundidade de 0 a $0,3 \mathrm{~m}$, na área 2 no ano de 2004, pode ser reforçada observando a quantidade acumulada das precipitações nos 30 dias antecedentes a coleta dos dados, com $88 \mathrm{~mm}$ no ano de 2003 e 284 mm no ano de 2004.

$\mathrm{A}$ variabilidade dos valores de $\mathrm{CE}$ nas duas áreas, evidenciada pelo $\mathrm{CV}$, segundo a classificação proposta por Warrick \& Nielsen (1980), é de valor médio. Após a análise de ajuste à distribuição normal pelo teste de Kolmogorov-Smirnov as distribuições da $\mathrm{CE}$ foram constatadas como sendo normais ao nível de 1\% de probabilidade (K-S), descrito por Campos (1976). O alto valor de curtose calculado, 
principalmente para a $\mathrm{CE}_{90}$, não prejudicou a caracterização da distribuição normal pelo teste K-S, pois a amostra possui grande quantidade de dados da distribuição e um pequeno número de valores extremos, perante o total de dados.

A verificação do ajuste à distribuição normal é uma etapa importante para todas as variáveis desse estudo, devido à posterior realização da análise de dependência espacial e interpolação por krigagem, que se beneficiam de distribuições mais simétricas em torno da média (Webster \& Oliver, 1990).

$\mathrm{O}$ teor de água, coletado na mesma ocasião em que se coletou a $\mathrm{CE}$, também foi analisado pela estatística descritiva e com base na metodologia proposta por Tukey (1977) analisou-se dados discrepantes. Na análise exploratória, observou que a área 1, ano 2003 e 2004 e a área 2, ano 2003 não apresentaram valores discrepantes. $\mathrm{Na}$ área 2, ano 2004, dois valores apresentaram-se abaixo do limite inferior, mas quando visualizados espacialmente junto com o mapa de argila, demonstraram indícios de que representam uma região diferenciada, não justificando suas exclusões. Já o único valor determinado como acima do limite superior na área 2, ano 2004, foi excluído, sendo que no croqui de campo também foram feitas anotações alertando sobre esse ponto amostral.

$\mathrm{Na}$ Tabela 5 é apresentada a estatística descritiva para os valores do teor de água e argila das duas áreas experimentais após a retirada dos dados discrepantes e da análise exploratória. 
Tabela 5. Estatística descritiva para os valores do teor de água e argila nas duas áreas experimentais

\begin{tabular}{lcccccc}
\hline \multirow{2}{*}{ Estatística } & \multicolumn{3}{c}{ Teor de água (\%) } & \multicolumn{2}{c}{ Argila (\%) } \\
& 2003 & 2004 & 2003 & 2004 & Área 1 & Área 2 \\
\hline$N^{0}$ de amostras & 83 & 84 & 63 & 32 & 42 & 92 \\
Mínimo & 10,29 & 9,19 & 9,51 & 10,14 & 11,50 & 16,10 \\
Máximo & 27,59 & 26,57 & 14,51 & 13,59 & 42,30 & 36,20 \\
Média & 16,16 & 15,60 & 12,42 & 12,20 & 21,50 & 23,09 \\
Mediana & 14,77 & 14,18 & 12,72 & 12,12 & 18,85 & 23,00 \\
Quartil inferior & 12,05 & 11,56 & 11,63 & 11,64 & 14,10 & 20,50 \\
Quartil superior & 19,05 & 18,97 & 13,51 & 12,99 & 29,50 & 25,00 \\
Desvio padrão & 4,62 & 4,76 & 1,34 & 0,89 & 9,13 & 3,66 \\
C.V. (\%) & 28,59 & 30,51 & 10,77 & 7,30 & 42,47 & 15,86 \\
Assimetria & 0,78 & 0,68 & $-0,46$ & $-0,27$ & 0,90 & 0,80 \\
Curtose & $-0,37$ & $-0,60$ & $-0,65$ & $-0,32$ & $-0,45$ & 1,48 \\
D & 0,13 & $0,13 *$ & 0,10 & 0,11 & 0,18 & 0,07 \\
\hline
\end{tabular}

* distribuição normal a 10\% probabilidade (Campos, 1976).

A estatística descritiva apresentada na Tabela 5 demonstra que o CV da argila na área 1 é maior do que na área 2, conseqüentemente os $\mathrm{CV}$ do teor de água na área 1, ano de 2003 e 2004, foram maiores em relação a área 2. Isto está associado as propriedades da argila em reter mais água (Raij et al., 1997). Comparando com os dados da Tabela 4 observa-se a mesma tendência nos valores obtidos da CE, maiores na área 1.

Embora o teste de K-S não permita caracterizar as distribuições do teor de água como normais, exceto a área 1 (2004), a simetria destas distribuições é evidenciada pelos valores de assimetria e curtose, cujos módulos não são elevados. Os valores de CV também atestam esta simetria, permitindo caracterizar estas variáveis como de média variação (Warrick \& Nielsen, 1980).

A estatística descritiva permite verificar que as distribuições dos dados do teor de água e argila assumem um comportamento muito próximo à distribuição 
normal teórica. Como salientado por Warrick et al. (1986), o ajuste de dados experimentais à distribuição teórica é apenas aproximado. Com base na estatística descritiva, foram assumidas as hipóteses necessárias à aplicação da geoestatística.

Para essas variáveis foi necessária uma maior atenção na etapa de interpolação dos dados pelo processo de krigagem, considerando, inclusive, a sua transformação logarítmica, procurando melhorar a eficiência no processo de interpolação. Esse resultado corrobora com aqueles apresentados por Cambardella et al. (1994) e Castro (2004), que para a maioria das variáveis do solo utilizadas em seus estudos, constataram uma não adequação à distribuição normal.

Para a análise da dependência espacial os semivariogramas foram calculados para as variáveis de $\mathrm{CE}$, teor de água e argila. Na Tabela 6 são apresentados os parâmetros do efeito pepita, patamar, alcance (m) e o componente estrutural $\left[\mathrm{C}_{1} /\left(\mathrm{C}_{0}+\mathrm{C}_{1}\right)\right]$, que indica o quanto da variação total dos dados é explicada pela continuidade espacial. Nos Anexos A1 e A2 estão demonstrados graficamente os semivariogramas. 
Tabela 6. Parâmetros dos semivariogramas dos valores de CE $\left(\mathrm{mS}^{-1} \mathrm{~m}^{-1}\right)$, teor de água (\%) e argila (\%) para as duas áreas experimentais

\begin{tabular}{|c|c|c|c|c|c|c|}
\hline Ano & Variável & Modelo & $\begin{array}{l}\text { Efeito Pepita } \\
\qquad\left(\mathrm{C}_{0}\right)\end{array}$ & $\begin{array}{c}\text { Patamar } \\
\left(\mathrm{C}_{1}\right)\end{array}$ & $\begin{array}{c}\text { Alcance } \\
\text { (a) }\end{array}$ & $\frac{\mathrm{C}_{1}}{\left(\mathrm{C}_{0}+\mathrm{C}_{1}\right)}$ \\
\hline \multicolumn{7}{|c|}{ Área 1} \\
\hline & $\mathrm{CE}_{30}$ & Esférico & 0,1352 & 2,805 & 135,9 & 0,95 \\
\hline \multirow[t]{3}{*}{2003} & $\mathrm{CE}_{90}$ & Esférico & 0,0455 & 0,558 & 128,4 & 0,92 \\
\hline & Teor de água & Esférico & 0,0001 & 0,063 & 168,7 & 0,99 \\
\hline & $\mathrm{CE}_{30}$ & Esférico & 0,1358 & 2,542 & 140,8 & 0,95 \\
\hline \multirow[t]{5}{*}{2004} & $\mathrm{CE}_{90}$ & Esférico & 0,0526 & 0,658 & 126,7 & 0,93 \\
\hline & Teor de água & Esférico & 0,0090 & 19,38 & 148,9 & 0,99 \\
\hline & Argila & Esférico & 0,0002 & 0,151 & 153,0 & 0,99 \\
\hline & \multicolumn{6}{|c|}{ Área 2} \\
\hline & $\mathrm{CE}_{30}$ & Exponenc. & 0,8284 & 0,491 & 24,5 & 0,37 \\
\hline \multirow[t]{3}{*}{2003} & $\mathrm{CE}_{90}$ & Exponenc. & 0,2141 & 0,205 & 39,7 & 0,49 \\
\hline & Teor de água & Esférico & 0,0001 & 0,012 & 185,4 & 0,99 \\
\hline & $\mathrm{CE}_{30}$ & Exponenc. & 0,6555 & 0,755 & 21,2 & 0,54 \\
\hline \multirow[t]{3}{*}{2004} & $\mathrm{CE}_{90}$ & Esférico & 10,4900 & 5,668 & 21,8 & 0,35 \\
\hline & Teor de água & Esférico & 0,0003 & 0,006 & 361,1 & 0,95 \\
\hline & Argila & Esférico & 0,0122 & 0,012 & 307,3 & 0,50 \\
\hline
\end{tabular}

Para nenhuma das variáveis foi avaliada a anisotropia, realizando-se todas as análises geoestatísticas utilizando-se os semivariogramas omnidirecionais, nos quais apenas a distância de separação entre as amostras é importante no cálculo da função semivariância e não o vetor de separação entre as mesmas.

O parâmetro componente estrutural é importante para se avaliar a eficiência da análise geoestatística, sendo um indicador consistente da variância estruturada $\left(\mathrm{C}_{1}\right)$ na dependência espacial das variáveis monitoradas. Utilizando esse critério, Cambardella et al. (1994) definiram classes distintas de dependência espacial. Se o componente estrutural for maior que 0,75 os autores consideram que a variável é considerada de elevada dependência espacial; entre 0,25 e 0,75 , média dependência e abaixo de 0,25 , baixa dependência espacial. 
$\mathrm{Na}$ área 1 todas as variáveis apresentaram elevada dependência espacial, com valores do componente estrutural elevados. $\mathrm{Na}$ área 2 apenas as variáveis teor de água 2003 e 2004 apresentaram elevada dependência espacial, sendo que as demais tiveram uma média dependência. Com exceção da $\mathrm{CE}_{90}$ (2004) as demais variáveis apresentaram o efeito pepita baixo, indicando que em distâncias de separação pequenas entre as amostras a variabilidade é pequena, o que significa que a distância de amostragem foi adequada.

O alcance é de fundamental importância para a interpretação de semivariogramas, pois indica a distância máxima que os pontos amostrais são relacionados (Vieira et al., 1983), sendo uma das principais utilizações dos semivariogramas a determinação do número ideal de amostras. $\mathrm{O}$ valor de alcance $(185,4 \mathrm{~m})$ observado para o teor de água na área 2 no ano de 2003 indica que a grade amostral empregada foi adequada e que na amostragem do ano de 2004 foi possível a diminuição da grade amostral, conseguindo-se, mesmo assim, captar a dependência espacial do teor de água.

Nos anexos A1 e A2, onde são apresentados os semivariogramas experimentais das variáveis $\mathrm{CE}$, teor de água e argila, é possível confirmar as diferenças entre as áreas estudadas. $\mathrm{Na}$ área 2 todas as variáveis apresentaram uma semivariância menor do que a área 1, indicando uma menor variabilidade dessas variáveis, também confirmadas pelos valores de CV na estatística descritiva.

Após a confecção dos semivariogramas, os parâmetros foram utilizados no processo de krigagem, gerando os mapas interpolados para as variáveis $\mathrm{CE}$, teor de água e argila na área 1 (Figura 5) e área 2 (Figura 6). 

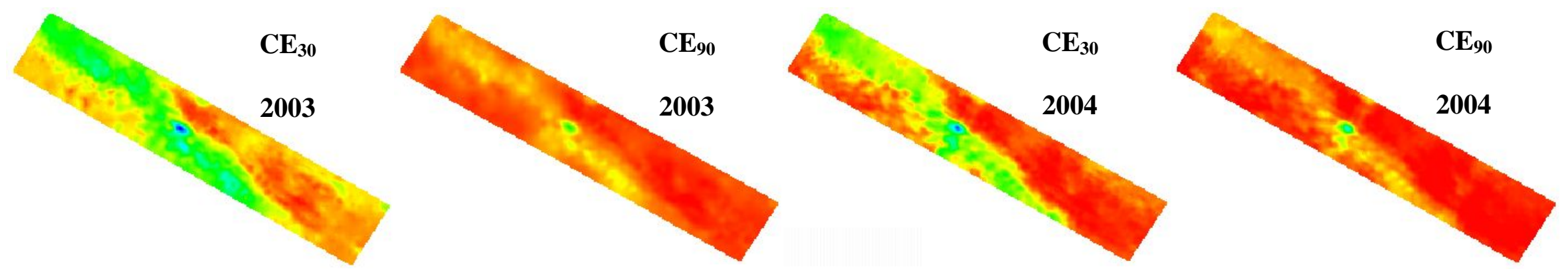

$$
\begin{array}{l|l}
\left(\mathrm{mS}^{-1} \mathrm{~m}^{-1}\right) \\
1,0 \\
\hline 12,0
\end{array}
$$

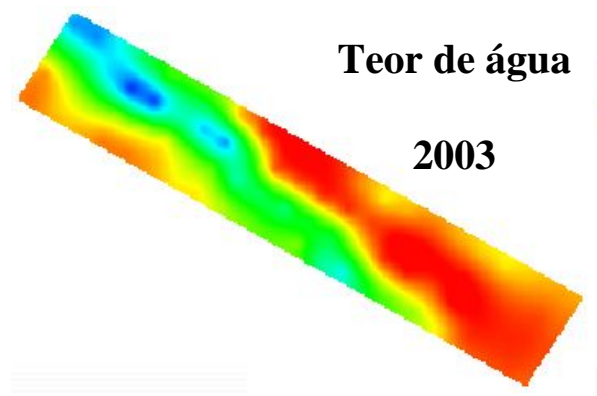

(\%)

10,0

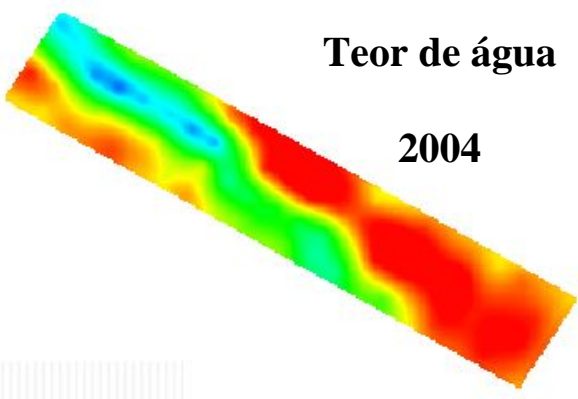

28,0
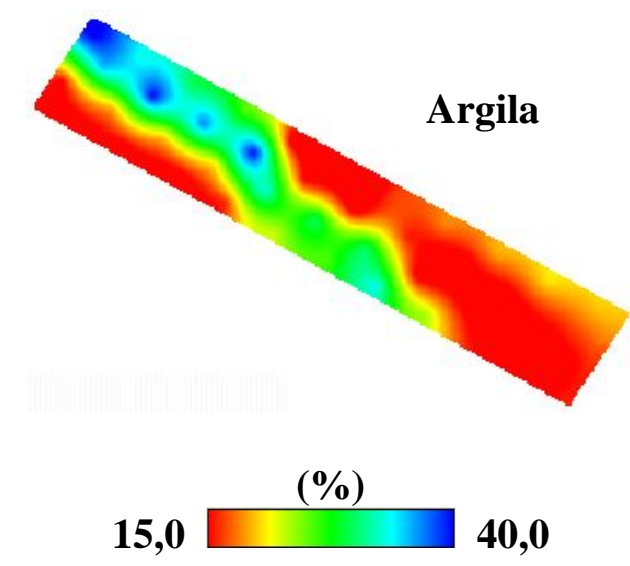

Figura 5 - Mapas da CE, teor de água e argila da área 1, interpolados pelo processo de krigagem 

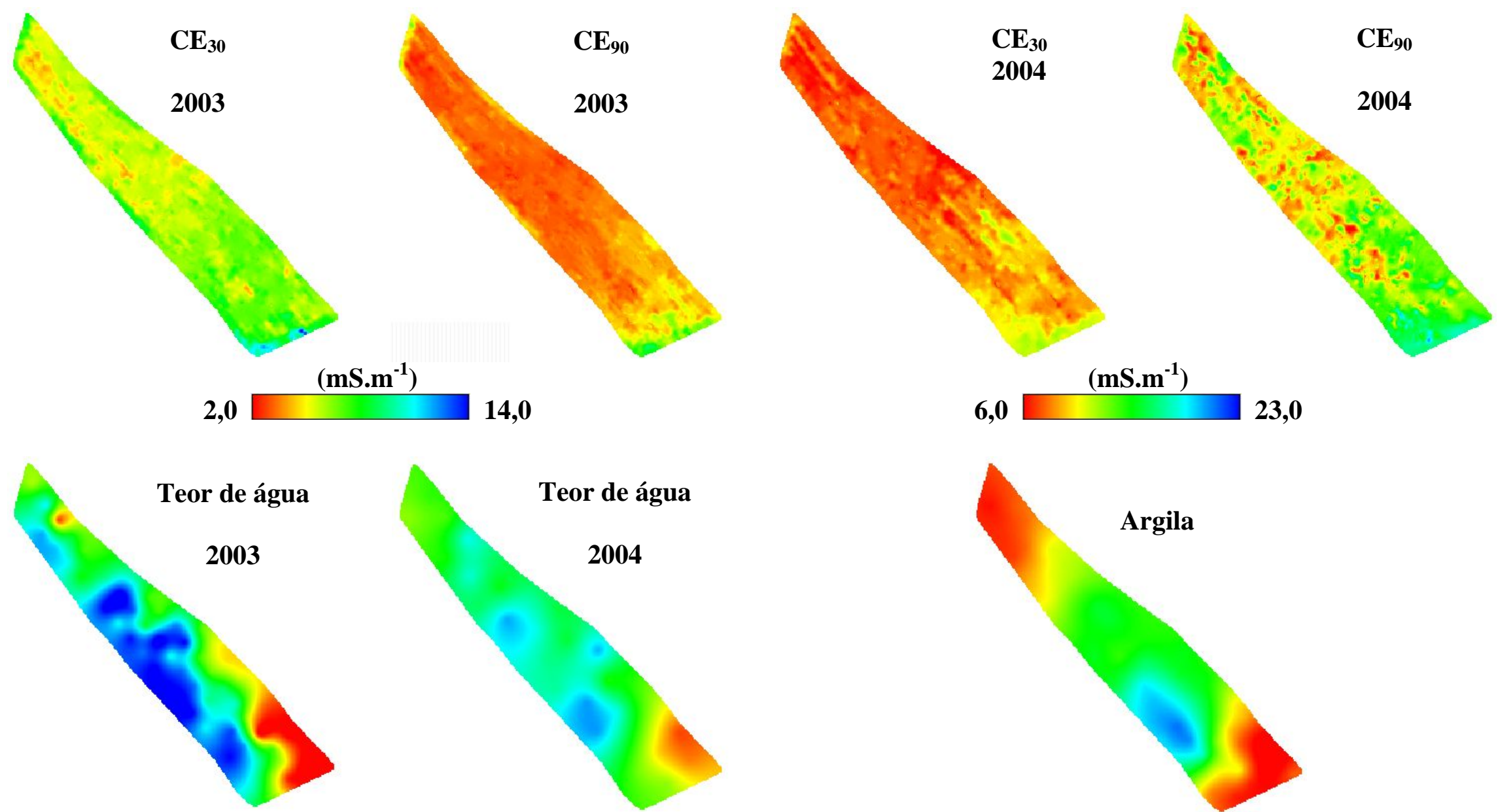

(\%)

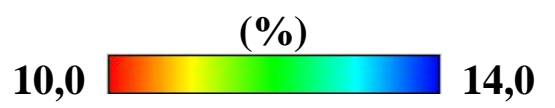

14,0

(\%)

Figura 6 - Mapas da CE, teor de água e argila da área 2, interpolados pelo processo de krigagem 
$\mathrm{Na}$ área 1 os mapas apresentam a mesma configuração das manchas da $\mathrm{CE}$, teor de água e argila. Já na área 2 é possível observar as amplitudes dos valores do teor de água e argila, bem menores do que na área 1. Sendo a CE influenciada pela argila e teor de água (Hendrickx et al., 1992; Rhoades et al., 1976), fica difícil diferenciar visualmente zonas distintas de $\mathrm{CE}$ como na área 1 . A CE na área 2 no ano de 2004 apresentou uma amplitude maior e valores mais elevados do que as outras medições, provavelmente pela maior precipitação acumulada nos 30 dias antecedentes a amostragem.

Os mapas interpolados do teor de água e argila da área 2, diferentemente da área 1, não apresentaram nenhuma relação visual com os mapas da CE. Pôde-se observar nos mapas interpolados do teor de água e argila algumas regiões em comum.

Através da regressão polinomial entre a $\mathrm{CE}_{30}$ e os teores de água e argila, foi possível obter o coeficiente de determinação $\left(\mathrm{r}^{2}\right)$ que expressa o quanto a $\mathrm{CE}_{30}$ é dependente do teor de água e da argila, para cada ano, nas duas áreas experimentais. Utilizando um primeiro conjunto de dados (conjunto 1) com os valores das variáveis interpolados por krigagem, foram obtidos os coeficientes de determinação das regressões polinomiais entre a $\mathrm{CE}_{30}$ e os teores de água e argila. A mesma análise de regressão foi feita para um segundo conjunto de dados (conjunto 2), os quais utilizam valores da $\mathrm{CE}_{30}$, compreendidos num raio de $15 \mathrm{~m}$ do ponto amostral do teor de água, para o cálculo de um valor médio da $\mathrm{CE}_{30}$ (variável dependente), obtendo coeficientes de determinação com os valores obtidos localmente sem as interpolações das variáveis teor de água e argila. Os coeficientes de determinação para os dois conjuntos de dados podem ser visualizado na Tabela 7 e os gráficos das regressões nos Anexos 3 e 4 para o conjunto de dados 1 e nos Anexos 5 e 6 para o conjunto de dados 2 . 
Tabela 7. Coeficiente de determinação $\left(\mathrm{r}^{2}\right)$ das regressões polinomiais da variável dependente $\left(\mathrm{CE}_{30}\right)$ com as variáveis independentes (teor de água e argila) nas duas áreas experimentais, para os dois conjuntos de dados

\begin{tabular}{|c|c|c|c|c|}
\hline \multirow{2}{*}{$\begin{array}{l}\text { Variável } \\
\text { dependente }\end{array}$} & \multirow{2}{*}{ Área } & \multirow{2}{*}{ Ano } & \multicolumn{2}{|c|}{ Coeficiente de determinação $\left(\mathrm{r}^{2}\right)$} \\
\hline & & & Teor de água & Teor de argila \\
\hline \multicolumn{5}{|c|}{ Conjunto de dados 1} \\
\hline \multirow{4}{*}{$\mathrm{CE}_{30}$} & \multirow{2}{*}{1} & 2003 & 0,78 & 0,75 \\
\hline & & 2004 & 0,75 & 0,73 \\
\hline & \multirow{2}{*}{2} & 2003 & 0,05 & 0,03 \\
\hline & & 2004 & 0,09 & 0,02 \\
\hline \multirow{5}{*}{$\mathrm{CE}_{30}$} & & \multicolumn{2}{|c|}{ Conjunto de dados 2} & \\
\hline & \multirow{2}{*}{1} & 2003 & 0,86 & 0,88 \\
\hline & & 2004 & 0,84 & 0,82 \\
\hline & \multirow{2}{*}{2} & 2003 & 0,07 & 0,07 \\
\hline & & 2004 & 0,03 & 0,04 \\
\hline
\end{tabular}

O teor de água no solo obteve um bom coeficiente de determinação com a $\mathrm{CE}_{30}$ somente na área 1. Fatores semelhantes também são citados por Lund et al. (1999) e Nehmdahl \& Greve (2001). Já na área 2 os coeficientes de determinação das regressões polinomiais foram próximos de zero nos dois anos amostrados. Isso ocorreu, provavelmente, pela menor amplitude nos valores do teor de argila.

Nos conjuntos de dados 1 e 2, observa-se elevados coeficientes de determinação na área 1 e coeficientes muito próximos a zero na área 2. É interessante ressaltar que os valores do coeficiente de determinação da regressão entre a $\mathrm{CE}_{30} \mathrm{e} o$ teor de água com a regressão da $\mathrm{CE}_{30}$ com o teor de argila são muito próximos, pois segundo Babalola (1978) e Ahuja e Nielsen (1990), a variabilidade do teor de água está relacionada com a variabilidade do teor de argila.

Analisando os dois conjuntos de dados utilizados para a análise de regressão, observa-se que o que utiliza valores médios da $\mathrm{CE}_{30}$ obtidos num raio de $15 \mathrm{~m}$ dos pontos amostrais do teor de água, possui, exceto na área 2 ano de 2004 para a relação entre a $\mathrm{CE}_{30}$ e o teor de água, valores mais elevados do coeficiente de determinação do que nas regressões que utilizaram o conjunto de dados interpolados. 
Também foram feitas análises de regressão para as variáveis teor de água no solo e teor de argila (Tabela 8), pois segundo Babalola (1978) e Ahuja e Nielsen (1990), a variabilidade do teor de argila resulta em variabilidade no teor de água no solo. Os gráficos das regressões podem ser visualizados no Anexo 7.

Tabela 8. Coeficiente de determinação $\left(\mathrm{r}^{2}\right)$ das regressões polinomiais da variável dependente (teor de água) com a variável independente (teor de argila) nas duas áreas experimentais

\begin{tabular}{cccc}
\hline $\begin{array}{c}\text { Variável } \\
\text { dependente }\end{array}$ & Área & Ano & $\begin{array}{c}\text { Coeficiente de determinação }\left(\mathrm{r}^{2}\right) \\
\text { Teor de argila }\end{array}$ \\
\hline \multirow{2}{*}{ Teor de água } & 1 & 2003 & 0,93 \\
& 2 & 2004 & 0,92 \\
& 2003 & 2004 & 0,36 \\
\hline
\end{tabular}

Nessa regressão fica evidente, na área 1, que a variação do teor de água é resultante em mais de $90 \%$ da variação no teor de argila. No entanto na área 2 os coeficientes de determinação não são muito elevados como na área 1 e diferem de um ano para o outro, pois no ano de 2004 o acumulado de precipitações foi três vezes maior que no ano de 2003 e com quantidades maiores de precipitação próximas à coleta dos dados.

Pela Tabela 8 também fica evidente a influência da quantidade de precipitação nos 30 dias antecedentes à coleta dos dados, ficando os valores amostrados da $\mathrm{CE}_{30}$ mais elevados na área 2 no ano de 2004 em relação aos valores coletados em 2003, visto que essa é influenciada pela quantidade de argila, a qual possui propriedades de retenção de água.

$\mathrm{Na}$ área 1 as relações entre as variáveis estudadas foram evidentes. $\mathrm{O}$ gradiente textural do solo é maior nessa área, em relação à área 2, com a argila variando de 15 a 40\%. A CE pode ser empregada, nessa área, como uma ferramenta para a demarcação de unidades de gerenciamento em função da argila do solo, visto a sua alta relação com o teor de água. 
As análises realizadas na área 2 demonstraram que o equipamento utilizado na mensuração da $\mathrm{CE}$ não detectou as pequenas variações do teor de argila (20 a $28 \%$ ), mesmo quando essa explicou em $65 \%$ a variação do teor de água no solo, como no ano de 2004. 


\section{CONCLUSÕES}

$\mathrm{Na}$ área 1 onde as amplitudes dos teores de argila e água são maiores, a variabilidade espacial da condutividade elétrica mostrou ser dependente do teor de água e conseqüentemente do teor de argila. $\mathrm{Na}$ área 2, o teor de água não apresentou influência na variabilidade espacial da condutividade elétrica, provavelmente, pelo fato da amplitude dos valores do teor de água e argila serem baixos. Por meio das regressões foi possível observar que grande parte da variação do teor de água no solo pode ser explicada pela variação do teor de argila, sendo essa relação, diferente em cada ano amostrado, como na área 2 , em função da quantidade de precipitação ocorrida nos dias antecedentes à coleta das amostras. 
ANEXOS 
Anexo 1 - Semivariogramas experimentais das variáveis $\mathrm{CE}$, teor de água e argila da área 1

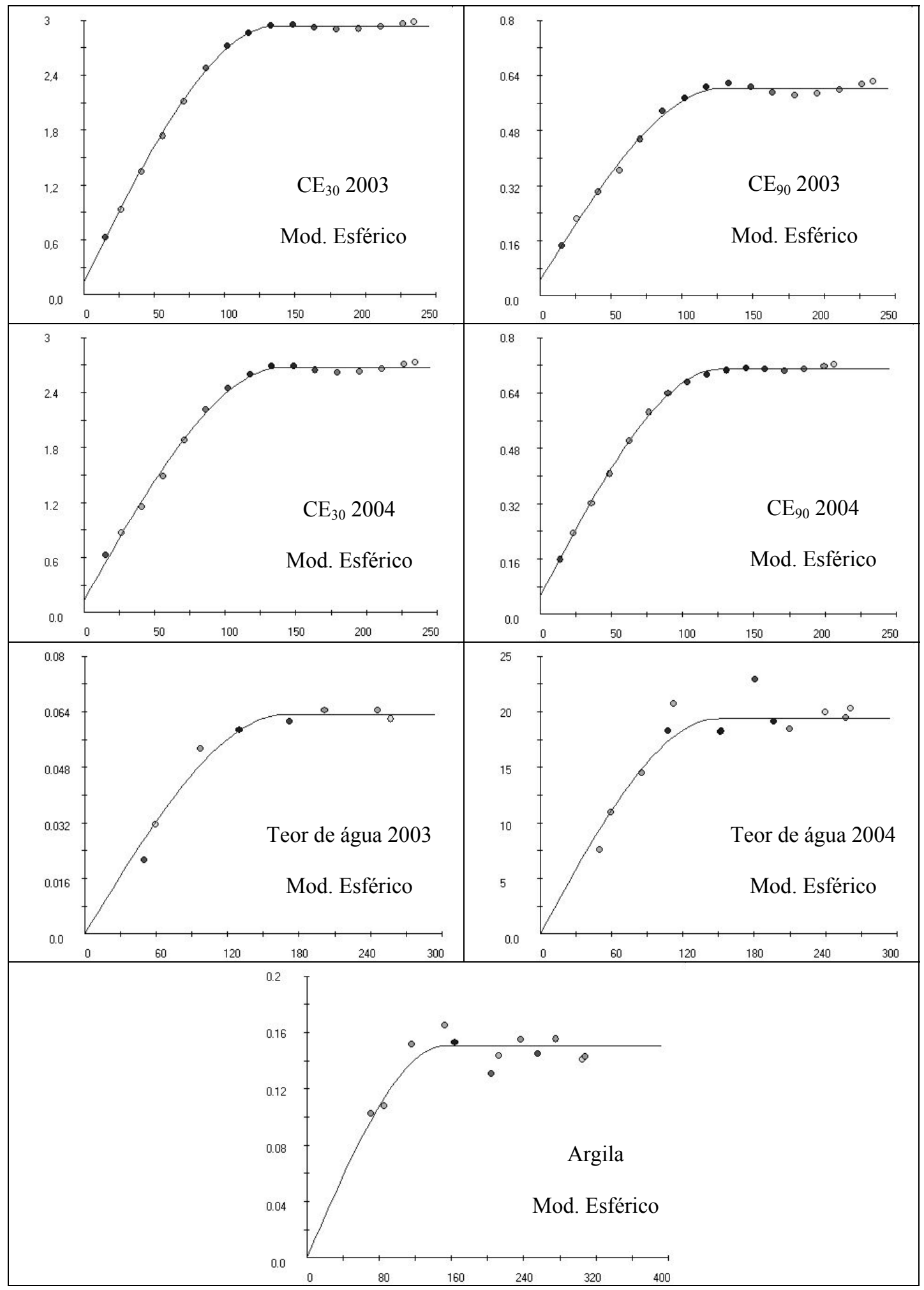


Anexo 2 - Semivariogramas experimentais das variáveis $\mathrm{CE}$, teor de água e argila da área 2

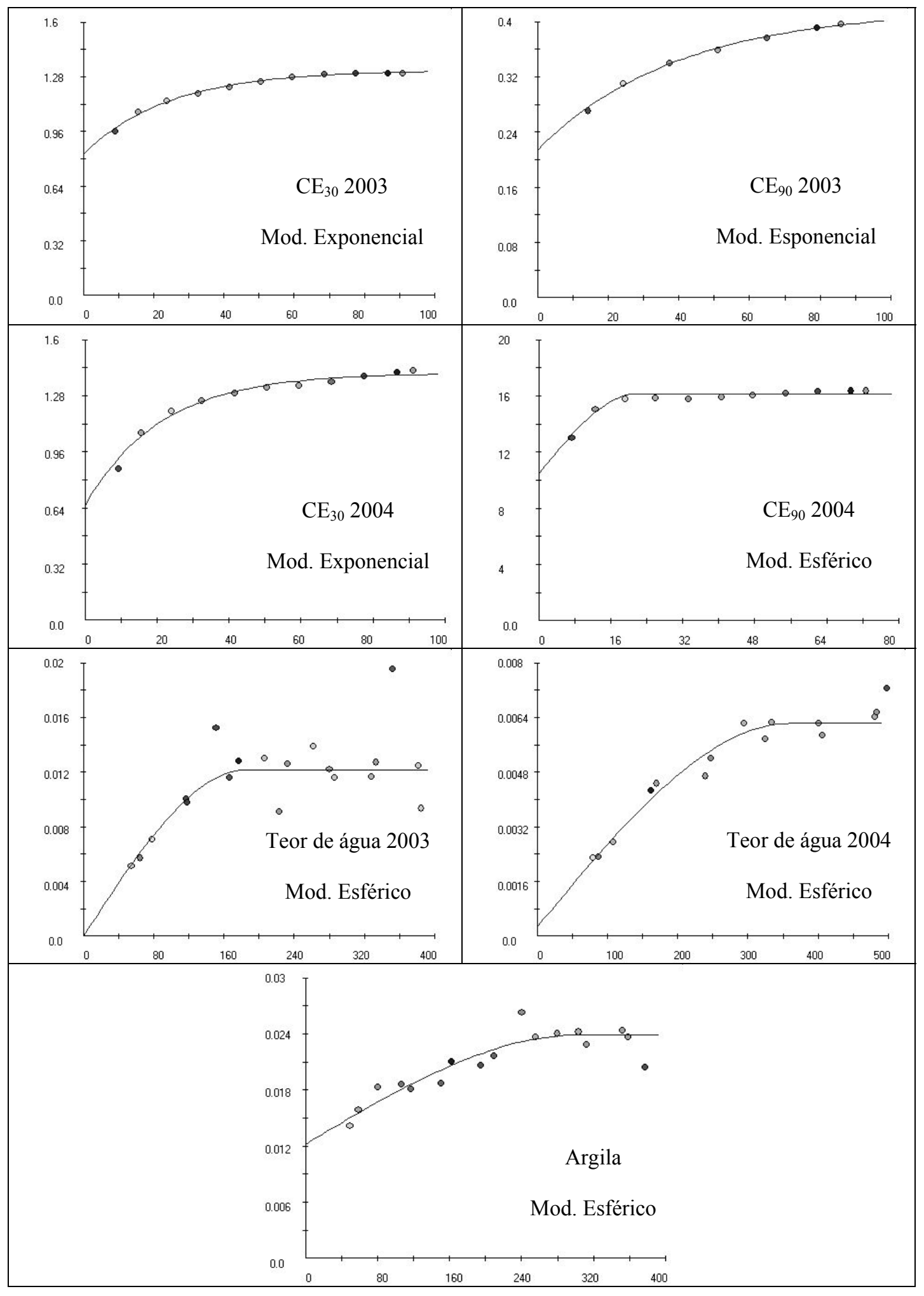


Anexo 3 - Gráficos das regressões polinomiais entre as variáveis $\mathrm{CE}_{30}$, teor de água e argila, na área 1 nos anos de 2003 e 2004 para o conjunto de dados 1

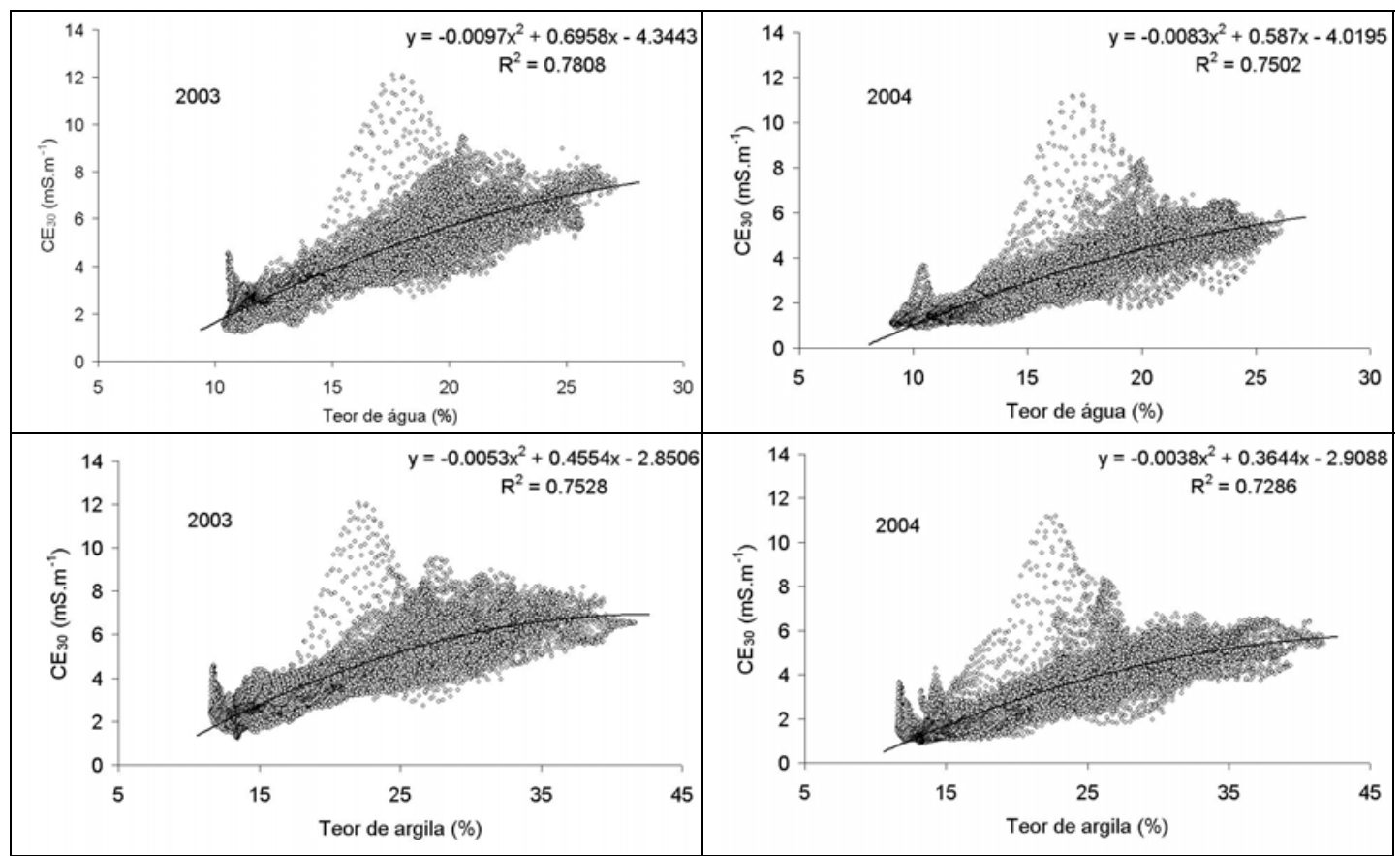

Anexo 4-Gráficos das regressões polinomiais entre as variáveis $\mathrm{CE}_{30}$, teor de água e argila, na área 2 nos anos de 2003 e 2004 para o conjunto de dados 1

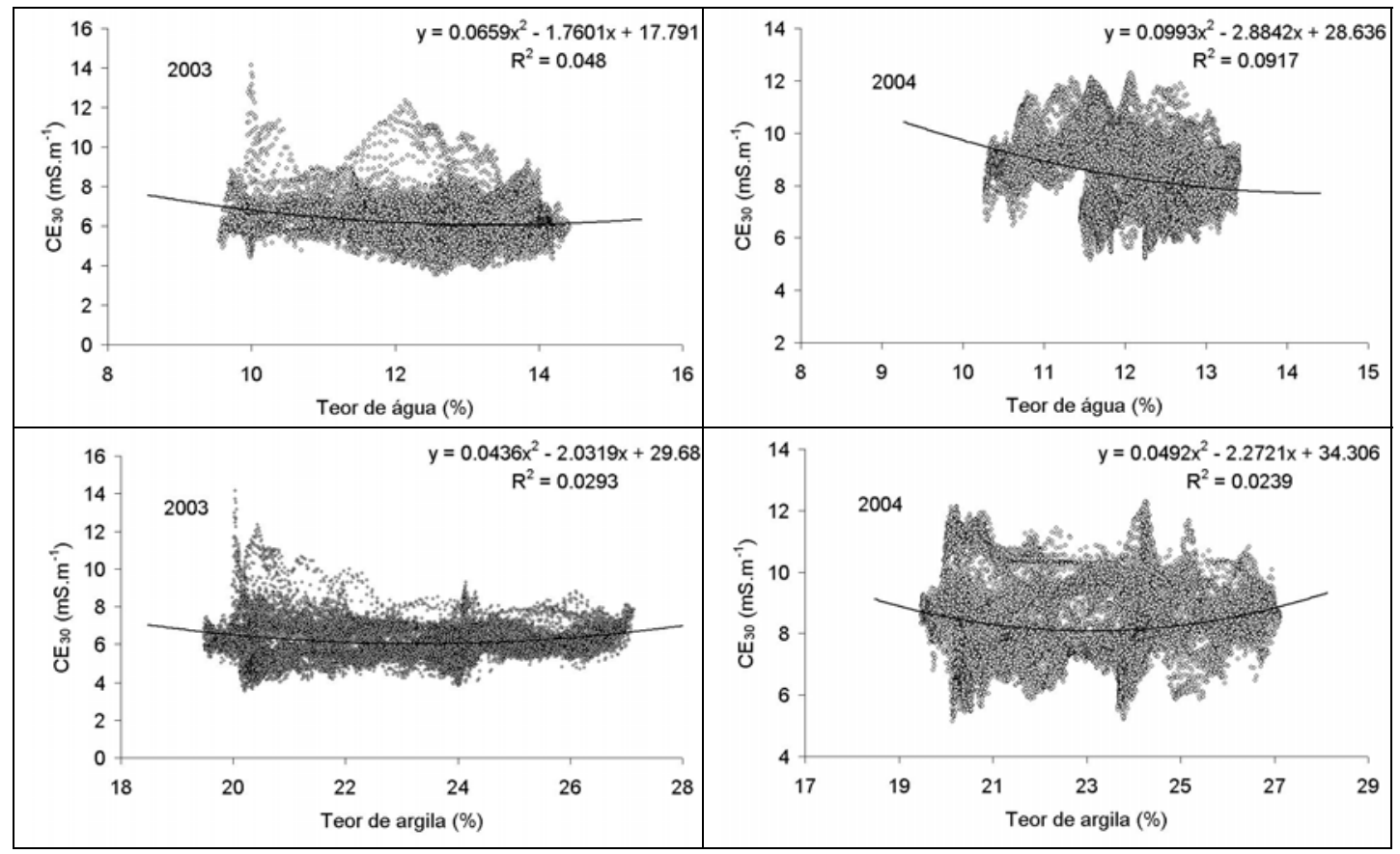


Anexo 5 - Gráficos das regressões polinomiais entre as variáveis $\mathrm{CE}_{30}$, teor de água e argila, na área 1 nos anos de 2003 e 2004 para o conjunto de dados 2

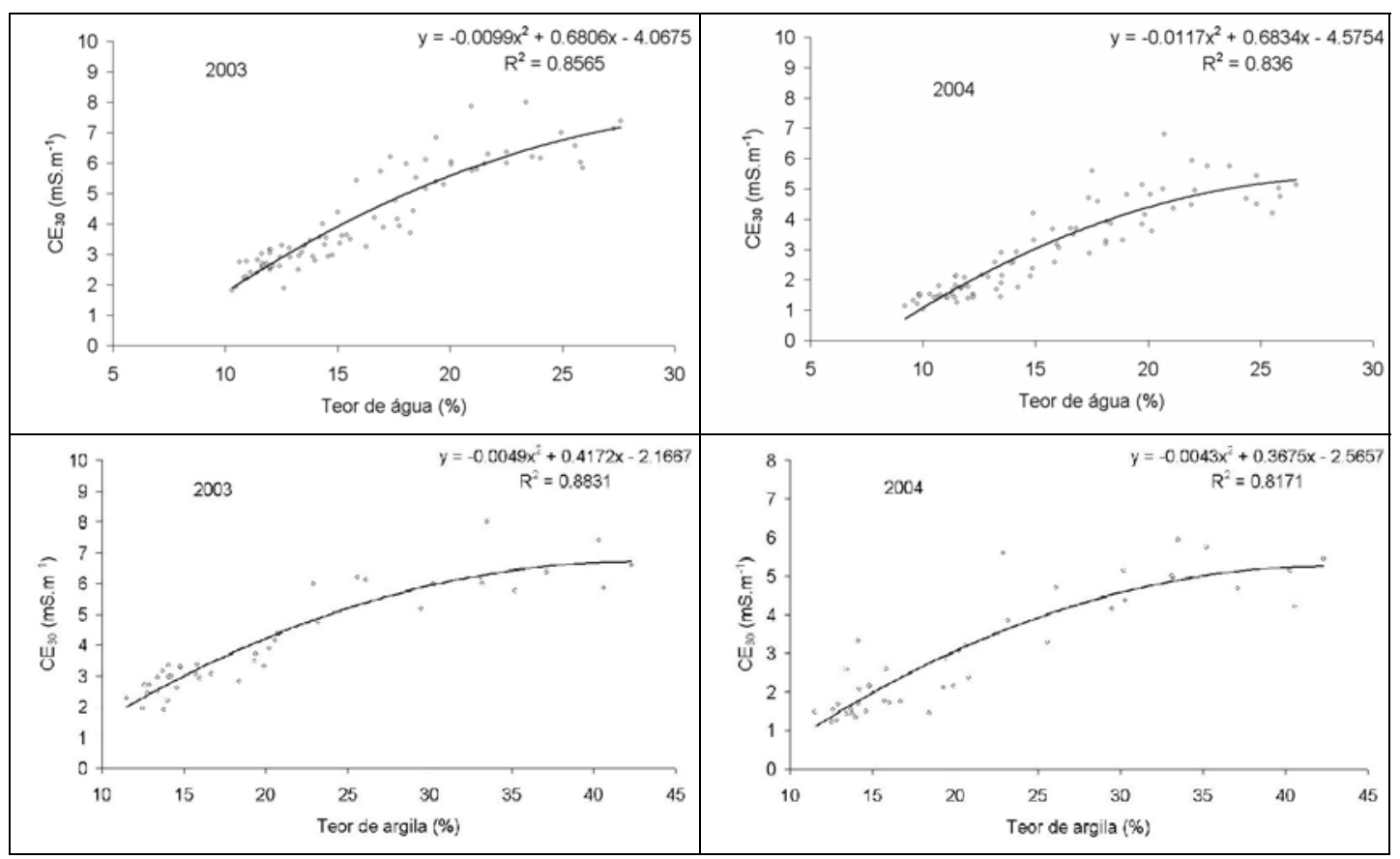

Anexo 6-Gráficos das regressões polinomiais entre as variáveis $\mathrm{CE}_{30}$, teor de água e argila, na área 2 nos anos de 2003 e 2004 para o conjunto de dados 2

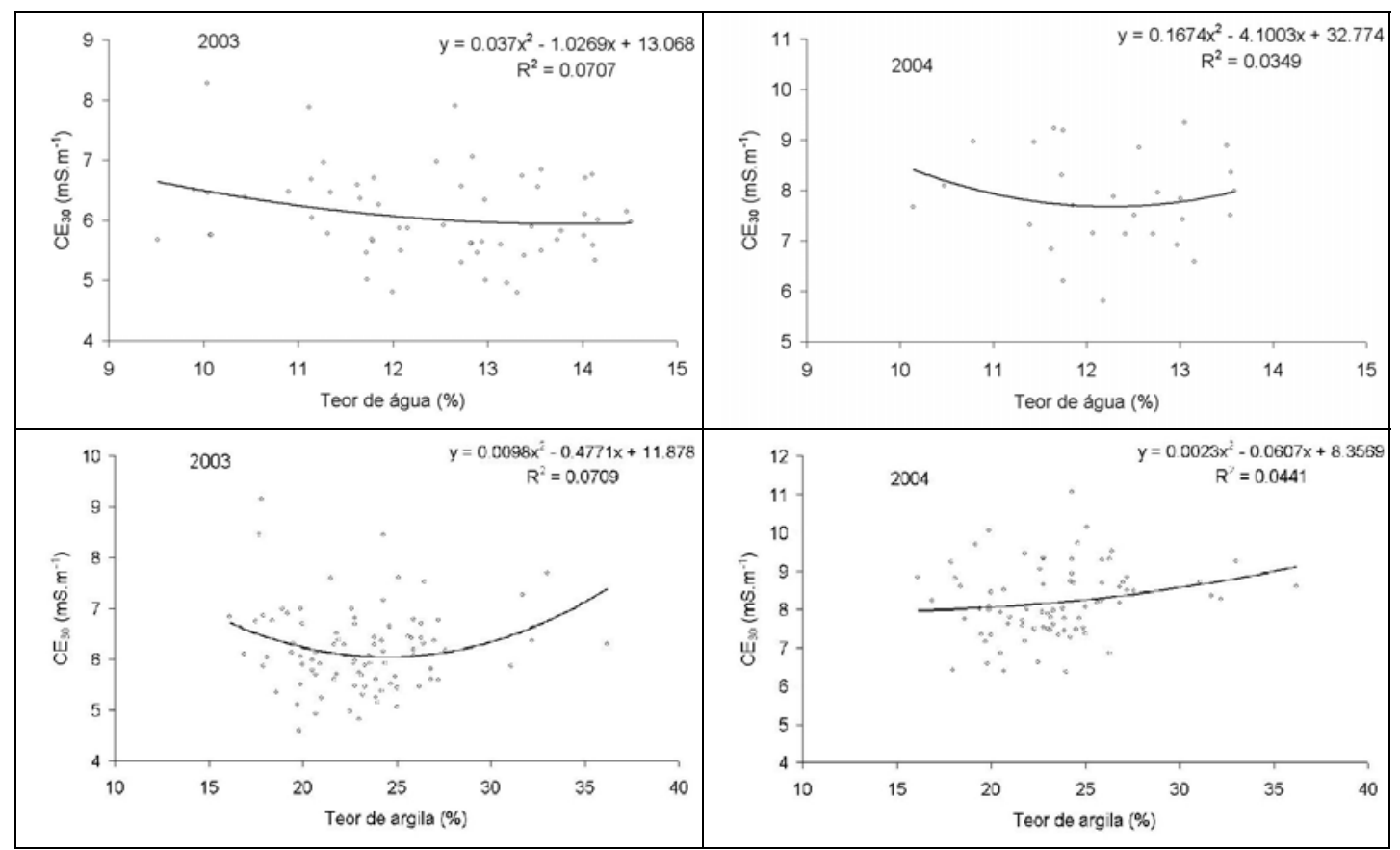


Anexo 7-Gráficos das regressões polinomiais entre as variáveis teor de água e argila, n as duas áreas experimentais, nos anos de 2003 e 2004 para o conjunto de dados 1

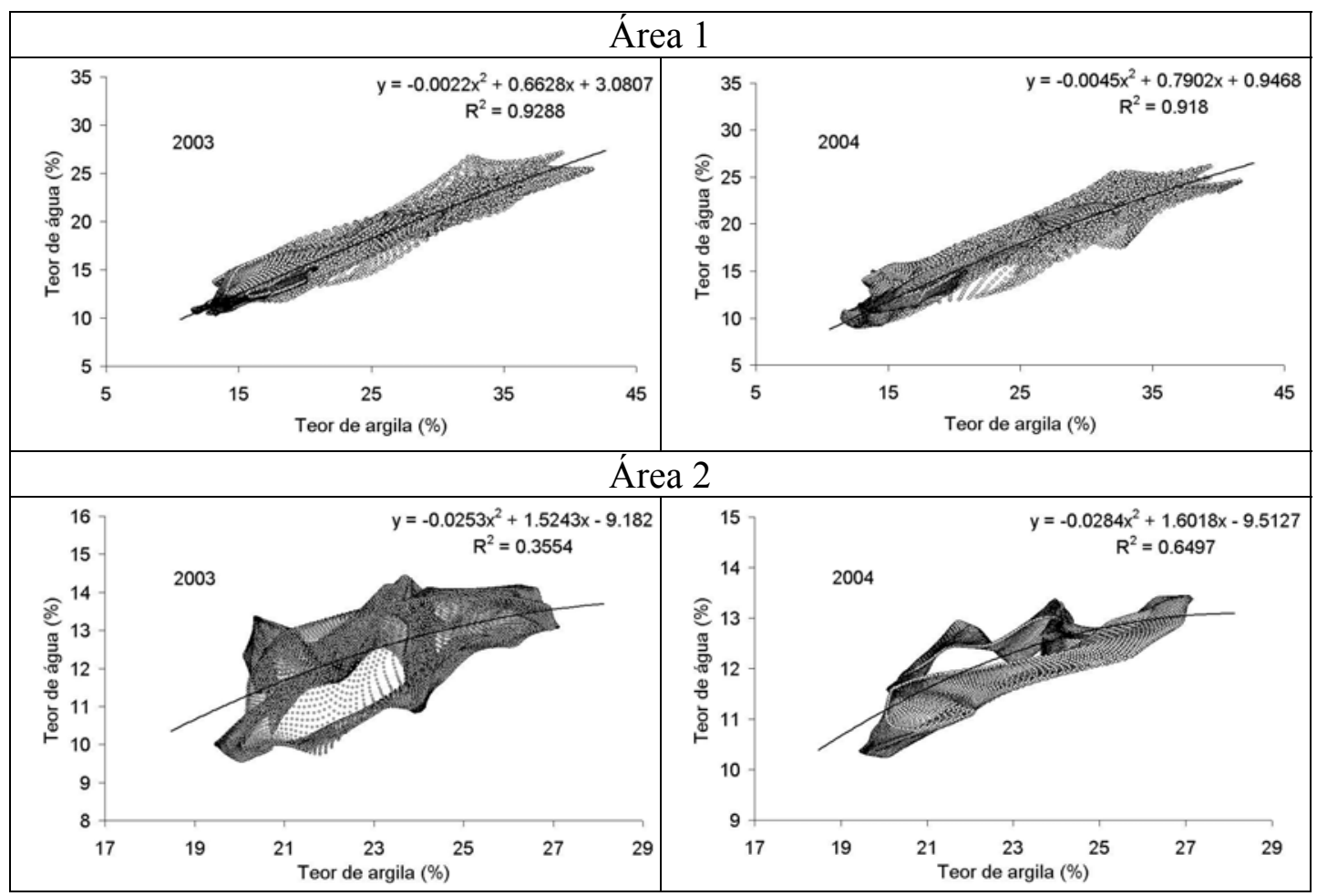




\section{REFERÊCIAS BIBLIOGRÁFICAS}

AHUJA, L.R.; NIELSEN, D.R. Field soil-water relations. In: STEWART, B.A.; NIELSEN, D.R. (Ed.). Irrigation of Agricultural Crops. Madison: Agronomy Monograph 30. 1990, cap. 7, p.143-189

ANDRADE, C.L.T.; COELHO, E.F.; COUTO, L.; SILVA, E.L. Parâmetros de soloágua para a engenharia de irrigação e ambiental. In: CONGRESSO BRASILEIRO DE ENGENHARIA AGRÍCOLA, 27., Poços de Caldas, 1998. Anais. Lavras: UFLA/SBEA, 1998. p. 1-132.

BABALOLA, O. Spatial variability of soil water properties in tropical soils of Nigeria. Soil Science, v. 126, n. 5, p.269-279, 1978.

BECKETT, P.H.T.; WEBSTER, R. Soil variability: a review. Soil and Fertilizers, v. 31, p. $1-15,1971$.

BOBERT, J.; SCHMIDT, F.; GEBBERS, R.; SELIGE, T.; SCHMIDHALTER, U. Estimating soil moisture distribution for crop managment with capacitance probes, EM-38 and digital terrain analysis (compact disc). In: EUROPEAN CONFERENCE ON PRECISION AGRICULTURE, 3., Montpellier, 2001. Proceedings. Montpellier: Ecole Nationale Supériure Agronomique, 2001.

BREVIK, E.C; FENTON, T.E. Soil sensing techniques as soil survey tools in lacustrine-derived soils, central Iowa (compact disc). In: INTERNATIONAL CONFERENCE ON PRECISION AGRICULTURE, 5., Bloomington, 2000. Proceedings. Bloomington: ASA;CSSA;SSSA, 2000. 
BUCHLEITER, G.W.; FARAHANI, H. Comparison of electrical conductivity measurements from two different sensing technologies. In: ANNUAL INTERNATIONAL MEETING. Illinois, 2002. Proceeding. Illinois: ASAE, 2002. 9 p.

BURGESS, T.M.; WEBSTER, R. Optimal interpolation and isarithmic mapping of soil properties. I. The semivariogram and punctual kriging. Journal Soil Science, v.31, p.315-331, 1980.

CAMBARDELLA, C.A.; MOORMAN, T.B.; NOVARK, J.M.; PARKIN, T.B.; KARLEN, D.L.; TURCO, R.F.; KONOPKA, A.E. Fiels-scale variability of soil properties in central Iowa soils. Soil Science of America Journal, v. 58, n. 5, p. $1501-1511,1994$.

CAMPOS, H. Estatística experimental não-paramétrica. Piracicaba: Esalq, 1976. $343 \mathrm{p}$.

CASTRO, C.N. Definição de unidades de gerenciamento do solo por meio da sua condutividade elétrica e variáveis físico-químicas. Piracicaba, 2004. 131 p. Dissertação (Mestrado) - Escola Superior de Agricultura "Luiz de Queiroz", Universidade de São Paulo.

CHRISTY, C.D.; LUND, E.D. Using electrical conductivity to provide answers for precision farming (compact disc). In: INTERNATIONAL CONFERENCE GEOSPATIAL INFORMATION IN AGRICULTURE AND FORESTRY, 1., Orlando, 1998. Proceedings. Orlando: s. ed., 1998. 8p.

DAVIS, J.G.; KIETCHEN, N.R.; SUDDUTH, K.A.; DRUMMOND, S.T. Using electromagnetic induction to characterize soils. Better crops with plant food, n. 4, p. 18-25, 1997.

DOERGE, T.; KITCHEN, N.R.; LUND, E.D. Soil electrical conductivity Mapping. Site-Specific Management Guidelines. n. 30. 2004. http://www.ppifar.org/ssmg. (16 mar. 2005). 
DOMSCH, H.; GIEBEL, A. Electrical conductivity of soils typical for the state of Bradenburg in Germany (compact disc). In: EUROPEAN CONFERENCE ON PRECISION AGRICULTURE, 3., Montpellier, 2001. Proceedings. Montpellier: Ecole Nationale Supériure Agronomique, 2001.

DOOLITTLE, J.A.; SUDDUTH, K.A.; KIETCHEN, N.R.; INDORANTE, S.J. Estimating depth to claypans using electromagnetic induction methods. Journal of Soil and Water Conservation, v. 49, n. 6, p. 572-575, 1994.

DORIA FILHO, U. Introdução a bioestatística: para simples mortais. São Paulo: Negócio, 1999. 152p.

DOURADO NETO, D. Variabilidade espacial das alturas de chuva e irrigação e de potenciais da solução do solo, 1989. 180p. Dissertação (Mestrado) - Escola Superior de Agricultura “Luiz de Queiroz”, Universidade de São Paulo.

EMPRESA BRASILEIRA DE PESQUISA AGROPECUÁRIA. Sistema brasileiro de classificação de solos. Brasília, 1999. 412p.

FLEMING, K.L.; WESTPHALL, D.G.; WIENS, D.W.; ROTHE, L.E.; CIPRA, J.E.; HEERMAN, D.F. Evaluating farmer developed management zone map for precision farming. In: INTERNATIONAL CONFERENCE ON PRECISION AGRICULTURE, 4., St. Paul, 1998. Proccedings. St. Paul: ASA; CSSA; SSSA, 1998. p. 335-343.

FRITZ, R.M.; MAIO, D.D.; SCHUMACHER, T.E.; CLAY, D.E.; CARLSON, C.G.; ELLSBURY, M.M.; DALSTED, K.J. Field comparison of two soil electrical conductivity measurement systems (compact disc). In: INTERNATIONAL CONFERENCE ON PRECISION AGRICULTURE, 4., St. Paul, 1998. Proceedings. St. Paul: ASA;CSSA;SSSA, 1998. p.1211-1217.

GEE, G.W.; BAUDER, J.W. Particle-size analysis. In: Methods of soil analysis. Madison: American Society of Agronomy, 1986. p.383-411. 
GOMIDE, R.L. Monitoramento para manejo da irrigação; instrumentos, automação e métodos. In: CONGRESSO BRASILEIRO DE ENGENHARIA AGRÍCOLA, 27., Poços de Caldas, 1998. Anais. Lavras: UFLA/SBEA, 1998, p. 133-238.

GONÇALVES, A.C.A. Geoestatística aplicada ao estudo da variabilidade espacial em ecossistemas. Curso de Especialização em Solos e Meio Ambiente. Maringá: Universidade de Maringá, 2000. 70p.

GONÇALVES, A.C.A.; MATA, J.D.V.; VIEIRA, S.R.; FOLEGATTI, M.V. Variabilidade espacial de produtividade e de resistência à penetração em área irrigada, sob dois sistemas de preparo. In: BALBUENA, R.H.; BENEZ, S.H.; JORAJURÍA, D. (Ed.). Avances em el manejo del suelo y agua em la ingeniería rural latinoamericana. La Plata: s. ed., 1998. p. 113-119.

GROSSI SAD, J.H. Fundamentos sobre variabilidade dos depósitos minerais. Rio de Janeiro: DNPM/CPRM - GEOSOL, 1986. 141p.

HAMELETT, J.M.; HORTON, R.; CRESSIE, N.A.C. Resistant and exploratory techniques for use in semivariogram analyses. Soil Science Society of America Journal, v.50, p. 868-875, 1986.

HARTSOCK, N.J.; MUELLER, T.G.; THOMAS, G.W.; BARNHISEL, R.I.; WELLS, K.L.; SHEARER, S.A. Soil electrical conductivity variability (compact disc). In: INTERNATIONAL CONFERENCE ON PRECISION AGRICULTURE, 5., Bloomington, 2000. Proceedings. Bloomington: ASA;CSSA;SSSA, 2000.

HENDRICKX, J.M.H.; BAERENDS, B.; RAZA, Z.I.; SADIG, M.; CHAUDHRY, M.A. Soil salinity assesmente by electromagnetic induction of irrigated land. Soil Science Society America Journal, v. 56, n. 6, p. 1933-1941. 1992.

HENDRICKX, J.M.H.; WIERENGA, P.J. Variability of soil water tension in a trickle irrigated chile pepper field. Irrigation Science, v. 11, n.1, p. 23-30, 1990.

ISAAKS, E.H.; SRIVASTAVA, R.M. Applied geostatistic. New York: Oxford University Press, 1989. 561p. 
JAYNES, D.B. Improved soil mapping using electromagnetic induction surveys. In: INTERNATIONAL CONFERENCE ON PRECISION AGRICULTURE, 3., Minneapolis, 1996. Proceedings Minneapolis: s. ed., 1996. p. 169-179.

JAYNES, D.B.; NOVAK, J.M.; MOORMAN, T.B.; CAMBARDELLA, C.A. Estimating herbicide partition coefficients from electromagnetic induction measurements. Journal of Environmental Quality,n. 24,p. 36-41, 1994.

KING, J.A.; DAMPNEY, P.M.R.; LARK, M.; MAYR, T.R.; BRADLEY, R.I. Sensing soil spatial variability by electromagnetic induction (EMI): it's potencial in precision farming (compact disc). In: EUROPEAN CONFERENCE ON PRECISION AGRICUlTURE, 3., Montpellier, 2001, Proceedings. Montpellier: Ecole Nationale Supériure Agronomique, 2001.

KITCHEN, N.R.; SUDDUTH, K.A.; DRUMMOND, S.T. Mapping of sand deposition from 1993 midwest floods with electromagnetic induction measurements. Journal of Soil and Water Conservation, v. 51, n. 4, p. 336-340, 1996.

LIBARDI，P.L.; PREVEDELlO， C.L.; PAUlETTO, E.A.; MORAES， S.O. Variabilidade espacial da umidade, textura e densidade de partículas ao longo de uma transeção. Revista Brasileira de Ciência do Solo, v.10, p.85-90, 1986.

LUND, E.D.; CHRISTY, C.D.; DRUMMOND, P.E. Practical applications of soil electrical conductivity mapping. In: EUROPEAN CONFERENCE ON PRECISION AGRICULTURE, 2., Odense, 1999. Proceedings. Odense: Elsevier, p. 771-780, 1999.

LUND, E.D.; COLIN, P.E.; CHRISTY, D.; DRUMMOND, P.E. Applying soil electrical conductivity technology to precision agriculture (compact disc). In: INTERNATIONAL CONFERENCE ON PRECISION AGRICULTURE, 4., St. Paul, 1998, Proceedings. St. Paul: ASA;CSSA;SSSA, 1998. p. 1089-1100. 
LUND, E.D.; COLIN, P.E.; CHRISTY, D.; DRUMMOND, P.E. Using yield and soil electrical conductivity maps to derive crop production performance information (compact disc). In: INTERNATIONAL CONFERENCE ON PRECISION AGRICULTURE, 5., Madison, 2000, Proceedings. Madison: ASA;CSSA;SSSA, 2000.

MACHADO, P.L.O.A.; SILVA, C,A.; BERNARDI, A.C.C.; CARMO, C.A.F.S.; VALENCIA,; L.I.O.; MEIRELLES, M.S.; MOLIN, J.P.; PAULETTI, V.; GIMENEZ, L.M. Técnicas de agricultura de precisão no diagnóstico de uma cultura de soja sob plantio direto em Carambeí, PR. Rio de Janeiro: Embrapa Solos, 2003. 29p. (Embrapa Solos, Boletim de Pesquisa e Desenvolvimento; $n$. 18). (Disponível em: http://www.cnps.embrapa.br/solosbr/conhecimentos.html).

MACHADO, R.V. Variabilidade espacial de atributos físico-hídricos em uma hidrosequência de solos bem à muito mal drenados, 1994. 88p. Dissertação (Mestrado) - Escola Superior de Agricultura de Lavras.

MANKIN, K.R.; EWING, K.L.; SCHROCK, M.D. Field measurement and mapping of soil salinity in saline seeps. In: ANNUAL INTERNATIONAL MEETING, Minneapolis. 1997. Proceedings. Miniapolis: ASAE, 1997. 10p.

MCBRIDE, R.A.; GORDON, A.M.; SHRIVE, S.C. Estimating forest soil quality from terrain measurements of apparent electrical conductivity. Soil Science Society of American Journal, v.54, p. 255-260, 1990.

MCKENZIE, R.C.; GEORGE, R.J.; WOODS, S.A.; CANNON, M.E.; BENNET, D.L. Use of the electromagnetic induction meter as a tool in managing salinisation. Hydrogeology Journal, v. 5, n. 1, p. 37-50, 1997.

MCNEIL, J.D. Geonics ground conductivity meter. Mississauga: Geonics, 1986. (Tech Note TN-21).

MINASNY, B.; MCBRATNEY, A.B.; WHELAN, B.M. Vesper version 1.6. Australian Centre for Precision Agriculture, The University of Sydney, 2002. http://www.usyd.edu.au/su/agri/acpa. (12 out. 2004). 
MOLIN, J.P.; COUTO, H.T.Z.; GIMENEZ, L.M.; PAULETTI, V.; MOLIN, R.; VIEIRA, S.R. Regression and correlation analysis of grid soil data versus cell spatial data. In: EUROPEAN CONFERENCE ON PRECISION AGRICUlTURE, 3., Montpellier, 2001, Proceedings. Montpellier: Agro Montpellier, 2001. p. 449-453.

NADLER, A.; FRENKEL, H. Determination of soil solution electrical conductivity from bulk soil electrical conductivity measurements by the four electrode method. Soil Science Society of American Journal, v.44, n.5, p. 1216-1221, 1980.

NEHMDAHL, H.; GREVE, M.H. Using soil electrical conductivity measurements for delineating management zones on highly variable soils in Denmark (compact disc). In: EUROPEAN CONFERENCE ON PRECISION AGRICULTURE, 3., Montpellier, 2001. Proceedings. Montpellier: Ecole Nationale Supériure Agronomique, 2001.

RAIJ, B. van; CANTARELlA, H.; QUAGGIO, J.A.; FURLANI, A.M.C. Recomendações de adubação e calagem para o Estado de São Paulo. Campinas: Instituto Agronômico e Fundação IAC, 1997. 285 p. (IAC. Boletim Técnico, 100).

RHOADES, J.D.; CORWIN, D.L. Measurement of inverted electrical conductivity profiles using electromagnetic induction. Soil Science Society of American Journal, v.44, p. 288-291, 1984.

RHOADES, J.D.; CORWIN, D.L. Soil electrical conductivity: effects of soil properties and application to soil salinity appraisal. Communed Soil Science Plant Annual, v. 21, p. 837-860, 1990.

RHOADES, J.D.; RAATS, P.A.C.; PRATHER, R.J. Effects of liquid-phase electrical conductivity, water content and surface conductivity on bulk soil electrical conductivity. Soil Science Society of America Journal. v. 40, p. 651-655, 1976. 
RUSSO, D.; BRESLER, E. Soil hydraulic properties as stochastic processes: I. An analysis of field spatial variability. Soil Science Society of America Journal, v. 45, n. 4, p. 682-687, 1981.

SHEETS, K.R.; HENDRICKX, J.M.H. Noninvasive soil water content measurement using electromagnetic induction. Water Resources Research, v. 31, n. 10, p. 2401-2409, 1995.

SOUZA, L.C. de. Variabilidade espacial da salinidade de um solo aluvial no semiárido paraibano. Campina Grande, 1999. 77p. Dissertação (Mestrado) Universidade Federal da Paraíba.

SUDDUTH, K.A.; KITCHEN, N.R.; DRUMMOND, S.T. Soil conductivity sensing on claypan soils: comparison of electromagnetic induction and direct methods. In: INTERNATIONAL CONFERENCE ON PRECISION AGRICULTURE, 4., St. Paul, 1998. Proceedings. St. Paul: ASA;CSSA;SSSA, 1998. p. 938-846.

TUKEY, J.W. Exploratory data analysis. Reading: Addilson-Wesley, 1977. 1v.

VIEIRA, S.R.; HATFIELD, J.L.; NIELSEN, D.R. et al. Geostatistical theory and application to variability of some agronomical properties. Hilgardia, v. 51, n. 3, p.1-75, 1983.

WARRICK, A.W.; MYERS, D.E.; NIELSEN, D.R. Geostatistical methods applied to soil science. In: KLUTE, A. (Ed.). Methods of soil analysis. 2 ed. Madison: Society of Agronomy/Soil Science of America. v. 9. 1986. p. 53-82.

WARRICK, A.W.; NIELSEN, D.R. Spatial variability of soil physical properties in the field. In: HILLEL, D.(Ed.). Applications of soil physics. New York: Academic Press, 1980. 385p.

WEBSTER, R.; OLIVER, M.A. Statistical methods in soil and land resourse survey. New York: Oxford University Press, 1990. 316p. 
WILLIAMS, B.G.; HOEY, D. The use of electromagnetic induction to detect the spatial variability of the salt and clay contents of soils. Australian Journal of Soil Research, v. 25, n. 1, p. 21-27, 1987. 